\title{
Therapeutic drug monitoring for triazoles: A needs assessment review and recommendations from a Canadian perspective
}

\author{
Michel Laverdiere* $M D^{1}$, Eric J Bow* $M D^{2}$, Coleman Rotstein* $M D^{3}$, Julie Autmizguine $M D^{4,5}$, Raewyn Broady $M D^{6}$, \\ Gary Garber $\mathrm{MD}^{7}$, Shariq Haider $\mathrm{MD}^{8}$, Trana Hussaini PharmD ${ }^{9}$, Shahid Husain $\mathrm{MD}^{3}$, Philippe Ovetchkine $\mathrm{MD}^{10}$, \\ Jack T Seki PharmD ${ }^{11,12}$, Yves Théorêt PhD ${ }^{5,13}$
}

\begin{abstract}
M Laverdiere, EJ Bow, C Rotstein, et al. Therapeutic drug monitoring for triazoles: A needs assessment review and recommendations from a Canadian perspective. Can J Infect Dis Med Microbiol 2014;25(6):327-343.

Invasive fungal infections cause significant morbidity and mortality in patients with concomitant underlying immunosuppressive diseases. The recent addition of new triazoles to the antifungal armamentarium has allowed for extended-spectrum activity and flexibility of administration. Over the years, clinical use has raised concerns about the degree of drug exposure following standard approved drug dosing, questioning the need for therapeutic drug monitoring (TDM). Accordingly, the present guidelines focus on TDM of triazole antifungal agents. A review of the rationale for triazole TDM, the targeted patient populations and available laboratory methods, as well as practical recommendations based on current evidence from an extended literature review are provided in the present document.
\end{abstract}

Key Words: Invasive fungal infection; Therapeutic drug monitoring; Triazole antifungal antibiotics

\section{La pharmacovigilance thérapeutique des triazoles : une analyse de l'évaluation des besoins et des recommandations dans le contexte canadien}

Les infections fongiques invasives sont responsables d'une morbidité et d'une mortalité importantes chez les patients atteints d'une maladie immunodépressive. L'ajout des nouveaux triazoles aux traitements antifongiques a élargi le spectre d'activité et la flexibilité d'administration. Au fil des ans, leur utilisation clinique a suscité des inquiétudes quant au degré d'exposition au médicament selon une posologie approuvée standard, ce qui soulève la nécessité de la pharmacovigilance thérapeutique (PVT). Les présentes lignes directrices portent donc sur la PVT des antifongiques triazolés. Dans le présent document sont exposées une analyse de la raison d'être de la PVT des triazoles, les populations de patients ciblées et les méthodes de laboratoire offertes, de même que des recommandations pratiques fondées sur des données probantes à jour tirées d'une analyse bibliographique approfondie.
Severely impaired host defense mechanisms represent the most important risk factor for invasive fungal infections (IFIs). Despite advances in antifungal pharmacology, the morbidity and mortality of IFIs remain unacceptably high (1). Appropriate antifungal therapy, proper management of the site of infection and improved host immune functions are essential to achieve successful outcome of IFIs. Clinicians' abilities to modulate and control the host immune functions are limited. In contrast, proper drug selection and dosing is entirely under the clinician's control. In clinical practice, therapeutic drug monitoring (TDM) is commonly performed in patients with bacterial infections and constitutes the standard of care for some antibiotics with a narrow therapeutic index such as vancomycin and the aminoglycosides $(2,3)$. Modification of drug dose after demonstration of inadequate exposure alters clinical outcome (4).
Triazoles constitute a significant proportion of antifungal antimicrobials commonly prescribed in Canada (5). Earlier first-generation antifungal triazoles have largely been supplanted by newer-generation extended-spectrum triazoles. Over the past decade, a considerable amount of information has accumulated about extended-spectrum triazoles following their addition to the Canadian antifungal armamentarium. Clinical experience with these agents based on standard approved drug dosing or weight-based regimens has provided insight into the importance of reproducible drug exposures and their relationship with successful clinical outcomes and drug safety (6).

The present review will focus on the relevance of TDM for extended-spectrum antifungal triazoles. First, the evidence supporting TDM indications will be presented, along with the patient populations in which clinical management supports a role for triazole TDM.

\section{*Co-Chairs}

${ }^{1}$ Department of Microbiology and Infectious Diseases, Hôpital Maisonneuve-Rosemont, Montreal, Quebec; ${ }^{2}$ Departments of Medical Microbiology and Infectious Diseases, and Internal Medicine, Sections of Infectious Diseases and Hematology/Oncology, Blood and Marrow Transplant, University of Manitoba, Winnipeg, Manitoba; ${ }^{3}$ Division of Infectious Diseases, Toronto General Hospital, University Health Network, University of Toronto, Toronto, Ontario; ${ }^{4}$ Service des Maladies Infectieuses, Département de Pédiatrie; ${ }^{5}$ Unité de Pharmacologie Clinique, CHU Ste-Justine, Montreal, Quebec; ${ }^{6}$ Division of Haematology, University of British Columbia, Vancouver, British Columbia; ${ }^{7}$ Division of Infectious Diseases, University of Ottawa/Ottawa Hospital, Ottawa; ${ }^{8}$ Hamilton Health Sciences, McMaster University, Hamilton, Ontario; ${ }^{9}$ Solid Organ Transplantation, Pharmaceutical Sciences Clinical Service Unit, Vancouver General Hospital, Vancouver, British Columbia; ${ }^{10}$ Service de Maladies Infectieuses, Département de Pédiatrie, CHU Sainte-Justine, Université de Montréal, Montreal, Quebec; ${ }^{11}$ Department of Pharmacy, Princess Margaret Cancer Centre, University Health Network; ${ }^{12}$ Leslie Dan Faculty of Pharmacy University of Toronto, Toronto, Ontario; ${ }^{13}$ Département de Pharmacologie, Université de Montréal, Montreal, Quebec

Correspondence: Dr Michel Laverdiere, Department of Microbiology-Infectious Diseases, Hôpital Maisonneuve-Rosemont, 5415 Boul de L'Assomption, Montreal, Quebec H1T 2M4. Telephone 514-252-3817, fax 514-252-3898, e-mail michel.laverdiere@umontreal.ca 


\begin{tabular}{|c|c|}
\hline Quality of evidence & Basis for recommendation \\
\hline High & $\begin{array}{l}\text { Further research is very unlikely to change our } \\
\text { confidence in the estimate of effect }\end{array}$ \\
\hline Moderate & $\begin{array}{l}\text { Further research is likely to have an important } \\
\text { impact on our confidence in the estimate of } \\
\text { effect and may change the estimate }\end{array}$ \\
\hline Low & $\begin{array}{l}\text { Further research is very likely to have an important } \\
\text { impact on our confidence in the estimate of effect } \\
\text { and is likely to change the estimate }\end{array}$ \\
\hline Very low & Any estimate of effect is very uncertain \\
\hline
\end{tabular}

Subsequently, laboratory azole-monitoring methods will be reviewed. Finally, practical recommendations regarding the application of triazole TDM will be proposed.

\section{METHODOLOGY}

The authors' working group was composed of specialists with expertise in infectious diseases, hematology/oncology, transplant medicine, pediatrics, clinical pharmacy and pharmacology, clinical microbiology, and clinical and medical biochemistry. A literature review of $>1900$ articles in English language available in Medline (1946 to 2013) and Embase (1974 to 2012) was undertaken using a combination of $>80$ primary search terms including the following: "fungal infections adults/pediatrics", "leukemia and bone marrow transplantation", "solid organ transplantation", "pharmacokinetics and pharmacodynamics", "therapeutic serum/plasma level", "plasma levels efficacy/toxicity", "CYP2C19 interactions", "slow/ rapid metabolizers", "high performance liquid chromatography" and "bioassay". Sources, methodology and MeSH terms are listed in Appendix 1. Sections of the planned document were assigned to primary author or coauthor pairs, who submitted separate preliminary manuscripts. These manuscripts were reviewed by the co-chair members and merged into a single draft document that was circulated among all authors for review and approval. An adapted Grading of Recommendations Assessment, Development and Evaluation (GRADE) system was used to assess the strength of the recommendation and quality of evidence (high, moderate, low and very low) to support each recommendation listed in the present review (7-9). The definitions of the quality of evidence of the GRADE system are summarized in Table 1. Two levels of recommendations are used: 'strong' when the benefits of the intervention clearly outweigh the undesirable effects; and 'weak' when the benefit of the intervention may be outweighed by undesirable effects.

All members of the working group complied with the Association of Medical Microbiology and Infectious Disease (AMMI) Canada policy on conflict of interest. Potential conflicts of interest are identified at the end of the document.

\section{RATIONALE FOR TDM}

Pharmacokinetic and pharmacodynamic considerations

TDM is indicated when the standard dosing of any given drug results in unpredictable exposures, or when relationships have been established between drug exposure (plasma drug level) and either efficacy or toxicity. Without these relationships, serum drug levels have no clinical relevance. Considerable differences exist between the pharmacokinetic (PK) and pharmacodynamic (PD) properties of various triazoles. Information related to these properties is reviewed relative to the need for TDM.

Fluconazole: Fluconazole is available in intravenous and oral formulations (tablet and suspension). The latter exhibits excellent bioavailability (10). Indeed, after oral administration, fluconazole has a bioavailability of $90 \%$, with essentially no first-pass metabolism (10).
Absorption of fluconazole is not affected by gastric $\mathrm{pH}$, fasting state, concomitant chemotherapy mucositis or gastrointestinal (GI) diseases, resulting in little variation in serum levels following oral administration (11). Fluconazole exhibits low plasma protein binding (12\%) and its apparent volume of distribution $(0.7 \mathrm{~L} / \mathrm{kg})$ approximates that of total body water (10) With its extensive distribution into body water and low affinity for plasma proteins, high concentrations of fluconazole are found throughout the body. The concentration of fluconazole in cerebrospinal fluid, saliva, sputum and vaginal fluid closely approximate that of plasma $(11,12)$. The plasma half-life of fluconazole is approximately $30 \mathrm{~h}$, and steady state is achieved within five to seven days following once-daily dosing (11). Approximately $80 \%$ of the administered dose is excreted by the kidneys as parent compound, reaching concentrations 10 - to 20 -fold higher in urine than in plasma (13). In the presence of renal dysfunction or during renal replacement therapy, fluconazole exposure is profoundly altered and appropriate dosage reductions are required (14). The PK relationship between oral dosing and fluconazole serum levels is linear in both healthy volunteers and immunocompromised cancer patients (13).

In summary, fluconazole is a water-soluble drug characterized by rapid absorption, high oral bioavailability, extensive tissue distribution and relatively high plasma concentrations. The direct correlation of fluconazole dose with blood levels provides for a highly favourable and predictable PK profile that does not support the use of TDM.

Itraconazole: Only the oral solution and capsule formulations of itraconazole are available in Canada. The bioavailability of itraconazole differs between the oral solution and the capsule formulation. Absorption of the capsule formulation is enhance by high-fat food and at acidic $\mathrm{pH}$ (15). Thus, dissolution of the capsules can be facilitated in the stomach using a cola drink or a vitamin C-containing beverage at an acidic $\mathrm{pH}$ between 1 and $4(16,17)$. Capsules should be administered soon after ingesting a meal to ensure optimal systemic absorption (18).

In contrast, the bioavailability of oral itraconazole solution is enhanced by the hydroxypropyl $\beta$-cyclodextrin formulation (19) and when administered in the fasting state (20).

Biomolecular barriers in the intestinal lumen impede drug absorption. Hall et al (21) documented two mechanisms that potentially reduce itraconazole absorption. The cytochrome P450 (CYP) isoenzyme CYP3A4 and P-glycoprotein (P-gp) are factors that account for some of the inter- and intrapatient variability in itraconazole absorption. Itraconazole is both a substrate for and potent inhibitor of P-gp and CYP3A4, and has the ability to raise plasma concentrations and enhance the effects of their substrates $(22,23)$. Hepatic metabolism of drugs by the CYP3A4 isoenzyme is well documented. In addition, the gene-regulated P-gp transporter-like pump actively removes drugs from enterocytes back into the intestinal lumen, limiting drug absorption. As with CYP3A4, there is significant inter- and intrapatient variation in the intestinal expression of P-gp $(21,24)$. Other factors that impact intrapatient variability of drug absorption and bioavailability include mucositis secondary to disease or chemotherapy, nausea and vomiting, dysphagia, inability to intake foods, and potential drug-drug or drug-food interactions. Cyclodextrin in itraconazole oral solutions may, of itself, produce intestinal toxicity (25). Less than $3 \%$ of cyclodextrin is absorbed from the gut, and $50 \%$ to $64 \%$ of cyclodextrin is excreted unaltered in the feces. Cyclodextrin may stimulate intestinal secretion, causing diarrhea (26). Drug accumulation in saliva may alter taste perception and negatively impact food intake $(25,27)$. In addition, itraconazole therapy has been associated with negative cardiac inotropic effects in several cases (28). Accordingly, precautions are suggested when long-term itraconazole treatment is considered in patients with ventricular dysfunction and a history of congestive heart failure.

The compound is $99.8 \%$ protein bound and has a volume of distribution of approximately $11 \mathrm{~L} / \mathrm{kg}$. Only $3 \%$ to $18 \%$ of the parent compound is excreted in the feces (15). The drug is extensively metabolized by the liver into $>30$ metabolites; however, 
hydroxy-itraconazole is the active metabolite of interest. Itraconazole elimination is biphasic with terminal half-lives reported at $24 \mathrm{~h}$ and $30 \mathrm{~h}$, after a single- or multiple-dose regimen, respectively. Steady state is reached after 14 days in healthy volunteers and may take as long to return to steady state after a dosage change. The nonlinear PK properties of itraconazole remains an important determinant of outcome (29). The affinity of itraconazole for the CYP, P-gp and uridine 5-diphosphate enzyme systems also accounts for significant drug interactions. Itraconazole TDM is of value for optimizing itraconazole dosing because of inter- and intrapatient PK variability despite the recommended therapeutic dosing ranges; intrinsic suboptimal absorption of itraconazole, particularly under circumstances of impaired GI integrity; oral intolerance producing poor compliance; and drug-drug interactions. These observations suggest that itraconazole TDM may be advisable in patients treated with itraconazole.

Voriconazole: Voriconazole, a triazole derived structurally from its predecessor, fluconazole (30), was developed to provide a broader spectrum of coverage against moulds (31-34). Voriconazole is available as intravenous and oral formulations (both tablet and suspension). Voriconazole possesses a saturable and nonlinear PK profile $(35,36)$. A dose-escalation study showed that accumulation and apparent nonlinear PKs of voriconazole are attributable to saturation of its metabolism and systemic clearance (37). Thus, a slight change in dose could produce a large change in plasma concentrations (38).

A steady-state level is achievable in three days with an initial twodose load given $12 \mathrm{~h}$ apart, followed by a maintenance dose administered twice daily, which should enhance the rate of response and, possibly, outcome (36). Without the loading doses, steady-state levels are achieved more slowly, over four to seven days (37).

In the absence of food, voriconazole oral formulations are rapidly and almost completely bioavailable (90\%) within $2 \mathrm{~h}$ of administration (35). However, food reduces voriconazole bioavailability by as much as $22 \%$, while a high-fat diet reduces area under the curve (AUC) by as much as $24 \%$ and the peak serum concentration (Cmax) by as much as $34 \%(39)$.

It is recommended that intravenous dosing of voriconazole be based on actual body weight. After either an intravenous or oral loading dose, a maintenance dose of $200 \mathrm{mg}$ orally twice daily is suggested for adults weighing $\geq 40 \mathrm{~kg}$. Nevertheless, the results of numerous PK studies have demonstrated wide inter- and intrapatient variations in the therapeutic levels associated with fixed maintenance-dose strategies (40-44). Fixed oral dosing of $200 \mathrm{mg}$ twice daily in patients weighing $\geq 40 \mathrm{~kg}$ has resulted in inadequate serum levels. Dosing adjustment of oral maintenance dose to values closer to $4 \mathrm{mg} / \mathrm{kg}$ twice daily has been recommended in patients with progressive IFIs (45).

Drug exposure in patients with a normal body mass index (BMI) may increase by 2.5-fold after an increase in dosage of $50 \%$, whereas the exposure is uncertain among patients with BMI $\geq 30 \mathrm{~kg} / \mathrm{m}^{2}$. In obese patients, dosing based on actual body weight may increase risk of overexposure and toxicity. Accordingly, it is recommended that intravenous and oral voriconazole dosing for obese subjects (class II obesity, BMI $\geq 35$ $\mathrm{kg} / \mathrm{m}^{2}$ ) should be based on ideal or adjusted body weight (46).

The CYP system critically affects the efficacy and toxicity of a number of drugs, including voriconazole. Voriconazole is both a substrate and an inhibitor of the following CYP systems: CYP2C19, CYP2C9 and CYP3A4 in the liver.

CYP2C19-mediated $\mathrm{N}$-oxidation is the major metabolic pathway for voriconazole (47). Interpatient variability of PK profiles of voriconazole has been linked to genetic polymorphisms in the CYP2C19 isoenzyme (48-52). Genetically determined metabolic groups define voriconazole kinetics as poor metabolizers (PM), heterozygous extensive metabolizers (HEM), extensive metabolizers (EM) and ultrarapid metabolizers (URM).

A spectrum of single-nucleotide polymorphisms leading to molecular variations in the structure of CYP2C19 is partly responsible for the interpatient variations of plasma levels. Within a given population, a CYP2C19*1 genotype may be classified as a homozygous EM or an HEM. Patients identified to have this allele exhibit slower metabolic rates (53). In contrast, patients with the CYP2C19*17 genotype are classified as URM. Heterozygous URM patients have been reported with a frequency of $18 \%$ to $22 \%$ among Swedish, Norwegian, Danish and Ethiopian individuals, and with a very low frequency $(4 \%)$ in Chinese individuals $(43,54)$. Healthy male Chinese volunteers who had this allele had higher clearances of oral voriconazole, resulting in lower AUCs and Cmax, and an increased risk for therapeutic failure (51).

The PM phenotype is defined for CYP2C19 by three different allele combinations (CYP2C19*2/*2, *2/*3/, *3/*3). PMs manifest significantly higher drug exposures than EMs or HEMs (55). The CYP2C19 PM genotype is more prevalent among Asian populations (15\% to $20 \%$ ) compared with Caucasians (2\% to 3\%) $(56,57)$.

Recently, a prospective evaluation in a mainly Caucasian population concluded that CYP2C19 and 2C9 genotypes were not major determinants of voriconazole metabolism (58)

Potentiation of drug-drug interactions may occur when voriconazole is coadministered with other drugs, especially when the drugs in question are competing for the same CYP enzyme systems (59).

Despite standard oral and intravenous voriconazole dosing, plasma levels $<1 \mathrm{mg} / \mathrm{L}$ may be observed in up to $50 \%$ of patients in whom TDM has been assessed (60). The unpredictability of the inter- and intrapatient drug concentration variations fulfills the PK criteria for the use of TDM-guided voriconazole dosing in clinical therapeutic decision making.

Posaconazole: Posaconazole is a lipophilic compound. While tablet and intravenous formulations have recently received regulatory approval, most posaconazole main PK/PD characteristics were determined using the oral formulation.

The PKs of posaconazole are characterized by enhanced absorption in a fatty environment, saturable absorption that significantly impacts its bioavailability, a long half-life and a linear elimination independent of CYP biotransformation (61). In healthy volunteers, posaconazole exhibits dose-proportional PK properties. Its absorption is slow and becomes saturable at $800 \mathrm{mg} /$ day; therefore, further dosage increases do not result in increased serum levels (62).

Administration of posaconazole oral solution formulation with food increases the mean AUC and Cmax by 2.6- and threefold, respectively. Coadministration with a high-fat meal increases bioavailability by fourfold compared with the fasting state (63). It is, therefore, recommended that posaconazole oral suspension be administered with a high-fat meal or a nutritional supplement in individuals who are unable to eat or tolerate a meal. Maintaining an acidic gastric environment also optimizes the absorption of posaconazole. A recent crossover study involving five healthy volunteers demonstrated that the coadministration of posaconazole suspension with an acidic cola beverage significantly increased posaconazole gastric concentrations $(+102 \%$; $<<0.001)$ and systemic exposure $(+70 \% ; \mathrm{P}<0.05)(64)$. It was suggested that these enhancements were caused by improved posaconazole solubility in the cola beverage and prolonged gastric residence. As expected, coadministration with a proton pump inhibitor, (esomeprazole) led to increased gastric $\mathrm{pH}$ and, therefore, decreased mean plasma and gastric AUC values by $37 \%$ and $84 \%$, respectively (64).

The new solid oral tablet formulation of posaconazole does not appear to have high-fat food-related administration or gastric acidity requirements to achieve adequate drug exposure (65).

Posaconazole is highly protein bound $(98 \%)$ with a large mean apparent volume of distribution $(1774 \mathrm{~L} / \mathrm{kg})$, indicating extensive extravascular distribution and penetration into intracellular spaces. A recent study involving 20 adult lung transplant recipients revealed a posaconazole concentration in alveolar cells ranging from 27 to 67 times higher than that observed in plasma; levels remained above the minimum inhibitory concentration (MIC) required to inhibit the growth of $90 \%$ of organisms for Aspergillus species throughout the measurement interval (66). 
Although posaconazole has a half-life of approximately $35 \mathrm{~h}$, due to its saturable absorption, the drug is optimally administered in divided daily doses, two to four times daily with no loading dose required (63). Steady-state concentration of posaconazole is achieved in seven to 10 days (62). Given the long half-life of this agent, multiple daily dosing schedules combined yield very little fluctuation in posaconazole serum concentrations once in steady state (67).

Posaconazole exhibits linear PKs. It is not extensively metabolized and circulates in plasma primarily as the parent compound (68). The metabolism of posaconazole is not mediated by CYP oxidation and, therefore, is not affected by coadministration of CYP inducers, inhibitors or by allelic variation as a result of CYP polymorphism. Phase II metabolism is responsible for biotransformation of a small fraction of posaconazole $(17 \%)$ into glucuronide conjugate. The drug is mostly (77\%) eliminated in the feces as unaltered drug, with only $14 \%$ eliminated as inactive metabolites in the urine. However, posaconazole inhibits CYP3A4 isoenzyme and P-gp, prompting interactions with drugs metabolized through these pathways (68). The PKs of posaconazole are not greatly affected by renal failure and no dosage adjustment is recommended in case of renal failure (69).

The PK properties of posaconazole show a marked intra- and interindividual variability, especially with regard to the bioavailability of the oral suspension. This variability is tributary to clinical situations. Gubbins et al (70) observed up to $68 \%$ variability in PK parameters in 30 neutropenic patients undergoing hematopoietic stem cell transplant (HSCT), attributing their findings to alterations in GI mucosa or reduced food intake. Patients with grade I and II mucositis had almost 50\% lower serum concentrations compared with those without mucositis. However, increasing the dosage to $200 \mathrm{mg}$ administered four times daily mitigated this effect. In another study involving 98 patients with refractory IFI or febrile neutropenia, exposure in bone-marrow transplant recipients was $52 \%$ lower than in non-bone-marrow transplant patients (71). The coefficient of variation for posaconazole serum concentrations was $>80 \%$ at steady state. Vehreschild et al (72) observed that the presence of diarrhea and concomitant use of pantoprazole significantly decreased posaconazole exposure (1.5- and 1.6-fold increase in apparent clearance, respectively) in acute myeloid leukemia (AML)/ myelodysplastic syndrome patients. The volume of distribution of posaconazole increases in direct proportion to patient weight, resulting in lower serum levels in heavier patients $(33.4 \mathrm{~L}$ larger apparent volume of distribution per $\mathrm{kg}$ ) (72).

Increasing age has been associated with higher posaconazole serum concentrations as a function of age-related reduced volumes of distribution (73). In a recent study, patients with hepatic impairment had an overall $36 \%$ increase in exposure (AUC) compared with the group of patients with normal hepatic function (74).

Although posaconazole exhibits linear and predictable PK properties with saturable absorption, gastric acidity and GI integrity influence its bioavailability. Cohorts of ill patients, patients receiving acidsuppressive therapy and those with mucositis or GI graft-versus-host disease (GVHD) experiencing diarrhea are likely to exhibit reduced posaconazole levels. On the other hand, elderly patients and those with hepatic impairment may exhibit higher posaconazole levels.

\section{Drug interactions}

Drug interactions are commonly reported when azoles are used concomitantly with other medications (75). PK interactions occur when one drug changes the way another drug is absorbed, distributed, metabolized or excreted. Most interactions associated with triazole therapy involve PK mechanisms.

The affinity of triazoles for the CYP, P-gp and uridine 5-diphosphate enzyme systems is the cause of the majority of significant drug interactions. Inhibition and induction of CYP isoenzymes in the liver and the epithelium of the gut, lungs, kidneys and brain are the most common mechanisms of these drug interactions. With itraconazole, the CYP3A4 isoenzyme is responsible for approximately $29 \%$ of human liver interactive activity and 70\% of GI CYP activity. Inhibition and induction of the P-gp efflux pump may also result in drug interactions, resulting in increased or decreased systemic exposure of concurrently administered drugs that are P-gp substrates. Of note, similar to their affinity for CYP enzymes, triazoles differ in their affinity for P-gp and their ability to inhibit P-gp. Immunosuppressive agents (IMs) (cyclosporine, tacrolimus, sirolimus) and other drugs, such as corticosteroids, chemotherapy agents, GI agents, cardiovascular agents, benzodiazepines, rifamycins and antidepressants, and certain foods may significantly affect or be affected by triazole interactions $(75,76)$. For example, grapefruit juice, through inhibition of CYP3A4 and, potentially, P-gp, can increase the serum level of itraconazole (77).

Voriconazole is both a substrate and an inhibitor of CYP isoenzymes. There is a long list of drugs that are potential targets for voriconazole drug-drug interactions including HIV protease inhibitors; vinca alkaloids such as vincristine, vinblastine, vindesine and vinorelbine; phenytoin; proton pump inhibitors; and IMs such as the calcineurin inhibitors (cyclosporine and tacrolimus) and the mammalian target of rapamycin inhibitors (sirolimus and everolimus). The plasma concentrations of IMs that are metabolized by the CYP3A4 isoenzymes are increased when coadministered with voriconazole due to the voriconazole-mediated inhibition of the CYP3A4-driven metabolic pathway. Accordingly, a 50\% reduction in cyclosporine and tacrolimus doses have been required to maintain a therapeutic range for these drugs $(59,78,79)$.

Certain over-the-counter complementary alternative medicines may interact with voriconazole. For example, self-administration of St John's wort (Hypericum perforatum) concurrently with voriconazole has been associated with an initial short-term increase of voriconazole plasma concentrations, followed by a prolonged extensive reduction of voriconazole exposure and an increased risk for voriconazole treatment failure (80).

Concomitant administration of rifamycins (rifabutin and rifampin) and voriconazole decreases voriconazole levels and increases rifamycin concentrations to potentially toxic levels. Guidelines caution against the concomitant administration of these two categories of antiinfective agents (81).

Posaconazole interferes essentially only with CYP3A4 isoenzyme and $\mathrm{P}$-gp and is, therefore, less implicated in drug-drug interactions (68). Phenytoin and rifabutin increase posaconazole's clearance $(82,83)$. The mechanism of this interaction is not well elucidated but may be due to P-gp induction.

In summary, triazole antifungal antibiotics have significant affinity for the CYP, P-gp and uridine 5-diphosphate enzyme systems, leading to important interactions in clinical practice. In most instances, the interference necessitates dosage adjustment of the nonazole drugs (Table 2). However, clinicians must also be cognisant of interactions that modify triazole disposition (Table 3). TDM and multidisciplinary management, including clinical pharmacist services, are components of safe and effective triazole antifungal therapy.

\section{Issues with efficacy and toxicity}

The in vitro activity of fluconazole limits its role to the treatment of Candida species and Cryptoccoccus species infections. Fluconazole has a predictable dosage-exposure relationship and low serum level variations. Accordingly, fluconazole TDM does not have a role in current practice.

A relationship between itraconazole serum concentration and efficacy has been observed by several investigators. For example, levels ranging from $0.25 \mathrm{mg} / \mathrm{L}$ to $1.0 \mathrm{mg} / \mathrm{L}$ have been associated with prophylaxis and IFI treatment efficacy $(84,85)$. However, few data support a linear relationship between serum levels and itraconazole toxicity. To date, there are no data that support a direct correlation between the rate of toxicity occurrences or hepatic abnormalities and itraconazole levels during treatment $(15,86)$. Serum concentrations of $>0.5 \mathrm{mg} / \mathrm{L}$ have been associated with an increased risk for GI intolerance (87) in multiple logistic regression analyses. Absorption and drug interaction issues have complicated the use of itraconazole in the prevention and 
TABLE 2

Effect of triazoles on coadministered drugs

\begin{tabular}{|c|c|c|c|c|}
\hline \multirow[b]{2}{*}{ Coadministered drug } & \multicolumn{4}{|c|}{ Effects of triazoles on coadministered drugs } \\
\hline & Voriconazole & Posaconazole & Itraconazole & Fluconazole \\
\hline $\begin{array}{l}\text { Cyclosporine (CSA) } \\
\uparrow \text { concentrations }\end{array}$ & $\begin{array}{l}\text { Dose of CSA should be } \\
\text { reduced to one-half of the } \\
\text { original dose }\end{array}$ & $\begin{array}{l}\text { Dose of CSA should be } \\
\text { reduced to three-quarters of } \\
\text { the original dose }\end{array}$ & $\begin{array}{l}\text { Dose of CSA may require a } \\
50 \% \text { reduction }\end{array}$ & $\begin{array}{l}\text { Careful monitoring of } \\
\text { immunossupressive drugs is } \\
\text { advised }\end{array}$ \\
\hline $\begin{array}{l}\text { Tacrolimus (TAC) } \\
\uparrow \text { concentrations }\end{array}$ & $\begin{array}{l}\text { Dose of TAC should be } \\
\text { reduced to one-third of the } \\
\text { original dose }\end{array}$ & $\begin{array}{l}\text { Dose of TAC should be } \\
\text { reduced to one-third of the } \\
\text { original dose }\end{array}$ & $\begin{array}{l}\text { Dose of TAC may require a } \\
\text { one-third reduction }\end{array}$ & \\
\hline $\begin{array}{l}\text { Sirolimus (SIR) } \\
\uparrow \text { concentrations }\end{array}$ & $\begin{array}{r}\text { Coadministration } \\
\text { contraindicated }\end{array}$ & $\begin{array}{l}\text { Theoretically monitor SIR } \\
\text { concentrations }\end{array}$ & $\begin{array}{l}\text { Dose of SIR may require } 50 \% \\
\text { to } 90 \% \text { reduction }\end{array}$ & \\
\hline Rifabutin $\uparrow$ concentrations & $\begin{array}{r}\text { Coadministration } \\
\text { contraindicated }\end{array}$ & $\begin{array}{r}\text { Coadministration } \\
\text { contraindicated }\end{array}$ & $\begin{array}{r}\text { Coadministration } \\
\text { contraindicated }\end{array}$ & Coadministration is not advised \\
\hline Phenytoin $\uparrow$ concentrations & $\begin{array}{l}\text { Frequent monitoring of } \\
\text { phenytoin levels is } \\
\text { recommended }\end{array}$ & Dosage reduction may be cons & idered. Frequent monitoring of $\mathrm{pl}$ & nenytoin levels is recommended \\
\hline $\begin{array}{l}\text { Ergot alkaloids } \\
\uparrow \text { concentrations }\end{array}$ & $\begin{array}{r}\text { Coadministration } \\
\text { contraindicated }\end{array}$ & $\begin{array}{r}\text { Coadministration } \\
\text { contraindicated }\end{array}$ & $\begin{array}{r}\text { Coadministration } \\
\text { contraindicated }\end{array}$ & $\begin{array}{r}\text { Coadministration } \\
\text { contraindicated }\end{array}$ \\
\hline $\begin{array}{l}\text { Vinca alkaloids } \\
\uparrow \text { concentrations }\end{array}$ & $\begin{array}{l}\text { Use with caution, following a } \\
48 \mathrm{~h} \text { wash-out period }\end{array}$ & $\begin{array}{l}\text { Use with caution, following a } \\
48 \mathrm{~h} \text { wash-out period }\end{array}$ & $\begin{array}{l}\text { Use with caution, following a } \\
48 \mathrm{~h} \text { wash-out period }\end{array}$ & $\begin{array}{l}\text { Dosage adjustment for vinca } \\
\text { alkaloids may be necessary }\end{array}$ \\
\hline $\begin{array}{l}\text { HMG-CoA reductase inhibitors } \\
\text { (statins) } \uparrow \text { concentrations }\end{array}$ & \multicolumn{4}{|c|}{ Statin dosage reduction may be necessary. Frequent monitoring for ADRs (rhabdomyolysis) is recommended } \\
\hline $\begin{array}{l}\text { Dihydropiridine calcium } \\
\text { channel blockers (CCB) } \\
\uparrow \text { concentrations }\end{array}$ & \multicolumn{4}{|c|}{ Monitor for signs of CCB toxicity. Dosage reduction may be necessary } \\
\hline $\begin{array}{l}\text { HIV protease inhibitors } \\
\uparrow \text { concentrations }\end{array}$ & \multicolumn{4}{|c|}{ Check individual agent. Monitor for signs of protease inhibitor toxicity } \\
\hline $\begin{array}{l}\text { Sulfonylurea oral } \\
\text { hypoglycemics } \\
\uparrow \text { concentrations }\end{array}$ & $\begin{array}{l}\text { Sulfonylurea dosage reduction } \\
\text { may be necessary. Monitor } \\
\text { for signs of hypoglycemia }\end{array}$ & - & - & - \\
\hline Midazolam $\uparrow$ concentrations & $\begin{array}{l}\text { Frequent monitoring of } \\
\text { oversedation is } \\
\text { recommended }\end{array}$ & $\begin{array}{l}\text { Dosage reduction should be } \\
\text { considered }\end{array}$ & Contraindicated & Careful monitoring is advised \\
\hline
\end{tabular}

TABLE 3

Effect of coadministered drugs on triazoles

\begin{tabular}{|c|c|c|c|c|}
\hline \multirow[b]{2}{*}{ Coadministered drug } & \multicolumn{4}{|c|}{ Effect on the triazole } \\
\hline & Voriconazole & Posaconazole & Itraconazole & Fluconazole \\
\hline $\begin{array}{l}\text { Cimetidine (pH effect and } \\
\text { CYP3A4 inhibitor }\end{array}$ & Not clinically significant & $\begin{array}{l}\downarrow \text { AUC by } 39 \% . \\
\text { Contraindicated }\end{array}$ & $\begin{array}{l}\downarrow \text { AUC. Acid-reducing agents } \\
\text { should be avoided }\end{array}$ & $\begin{array}{l}\downarrow \text { serum level only with oral } \\
\text { administration }\end{array}$ \\
\hline $\begin{array}{l}\text { Rifabutin (UDP-G and } \\
\text { CYP inducer) }\end{array}$ & $\begin{array}{l}\downarrow \text { serum level } \\
\text { Contraindicated }\end{array}$ & $\begin{array}{l}\downarrow \text { AUC by } 50 \% \text {. } \\
\text { Contraindicated }\end{array}$ & $\downarrow$ serum level by $90 \%$ & - \\
\hline $\begin{array}{l}\text { Phenytoin (UDP-G and } \\
\text { CYP inducer) }\end{array}$ & $\begin{array}{l}\downarrow \text { serum level } \\
\text { Increase empirical dosage } \\
\text { TDM recommended }\end{array}$ & $\begin{array}{l}\downarrow \text { AUC by } 50 \% \text {. } \\
\text { Contraindicated }\end{array}$ & $\downarrow$ serum level by $90 \%$ & - \\
\hline Carbamazapine & $\begin{array}{l}\downarrow \text { serum level } \\
\text { Contraindicated }\end{array}$ & - & $\begin{array}{l}\downarrow \text { serum level } \\
\text { Contraindicated }\end{array}$ & - \\
\hline $\begin{array}{l}\text { HIV protease inhibitors } \\
\text { (CYP inhibitor) }\end{array}$ & $\begin{array}{l}\uparrow \text { serum level } \\
\text { TDM recommended }\end{array}$ & - & $\begin{array}{l}\uparrow \text { serum level } \\
\text { Check individual agents. } \\
\text { May need to limit itraconazole } \\
\text { dose to } 200 \mathrm{mg} / \text { day }\end{array}$ & $\begin{array}{l}\text { Unlikely. Check individual } \\
\text { agents }\end{array}$ \\
\hline Ritonavir (CYP inducer) & $\begin{array}{l}\downarrow \text { serum level } \\
\text { Administration with high-dose } \\
\text { ritonavir is contraindicated } \\
\text { TDM with low-dose ritonavir }\end{array}$ & - & $\begin{array}{l}\uparrow \text { serum level } \\
\text { Limit itraconazole dose to } \\
200 \mathrm{mg} / \text { day }\end{array}$ & - \\
\hline
\end{tabular}

AUC Area under the curve; CYP Cytochrome P450; TDM Therapeutic drug monitoring; UDP-G UDP-glucuronidase

treatment of aspergillosis. With the advent of second-generation triazoles, itraconazole is now commonly considered to be a second choice in the management of IFI.

Voriconazole is a triazole antifungal with in vitro activity against clinically relevant Candida species and filamentous fungi, notably
Aspergillus species, Fusarium species (excluding Fusarium solani and Fusarium verticilloides) and Scedosporium species. Voriconazole is a firstline therapy for the management of proven and probable invasive aspergillosis (IA) $(88,89)$, with complete and partial response rates of $52.8 \%$ compared with $31.6 \%$ for amphotericin B deoxycholate, and a 
12-week survival benefit of $70.8 \%$ versus $57.9 \%$ in favour of voriconazole in a randomized trial that permitted switching to other licensed antifungal therapy (90). Voriconazole is indicated for the treatment of candidemia and invasive candidiasis $(89,91-93)$. Voriconazole has also been used for prophylaxis against IFI in allogeneic stem-cell transplant patients (greater success was observed with voriconazole than itraconazole, but no difference in rates of proven or probable IFI and overall survival at day 180 were observed compared with fluconazole) $(94,95)$. As empirical antifungal therapy in patients with persistent neutropenic fever syndrome, voriconazole failed to achieve noninferiority compared with liposomal amphotericin B but did reduce breakthrough IFI (96). Voriconazole serum levels ranging from $0.5 \mathrm{mg} / \mathrm{L}$ to $5.5 \mathrm{mg} / \mathrm{L}$ have been associated with clinical response, decreased breakthrough infections and decreased mortality $(6,41,42,97-101)$. However, a variation of more than10-fold has been reported, caused, in part, by considerable heterogeneity among voriconazole's indications (targeted versus empirical versus pre-emptive therapy) and by clinical parameters used by investigators to assess efficacy and toxicity.

Posaconazole is an expanded-spectrum triazole with in vitro activity against clinically relevant Candida species, filamentous fungi including Aspergillus species, and the more common members of the order Mucorales, particularly Rhizopus species. Posaconazole has been studied as salvage therapy for IA (102), and as prophylaxis against IFI compared with fluconazole or itraconazole in high-risk AML patients (103) and patients with acute or chronic GVHD (104). Posaconazole prophylaxis in AML was associated with a reduction in IFI from $8 \%$ to $2 \%$, particularly for IA, and with a relative risk reduction of $32.6 \%$ in all-cause mortality at day 100 (103). No survival benefit was noted in stem-cell transplant recipients (104). Data collected during two antifungal prophylaxis clinical licensing trials were retrospectively analyzed to assess the exposure efficacy of posaconazole $(67,105)$. In HSCT recipients with GVHD, protective serum levels ranged from $0.9 \mathrm{mg} / \mathrm{L}$ to $1.36 \mathrm{mg} / \mathrm{L}$, while in AML patients undergoing chemotherapy, the average protective level against IFIs was $0.5 \mathrm{mg} / \mathrm{L}$. Although definitive conclusions on the protective levels of posaconazole prophylaxis could not be clearly established, a putative target steady-state plasma level $\geq 0.7 \mathrm{mg} / \mathrm{L}$ was proposed (106). In postmarketing evaluations of posaconazole prophylaxis, plasma levels $\geq 0.5 \mathrm{mg} / \mathrm{L}$ have been protective against proven and possible fungal infections $(107,108)$.

Similar to antifungal prophylaxis trials, treatment trials to establish exposure-efficacy relationships for posaconazole are very limited. In a therapeutic salvage trial of IA, posaconazole mean maximum and average plasma concentrations of $1.5 \mathrm{mg} / \mathrm{L}$ and $1.2 \mathrm{mg} / \mathrm{L}$, respectively, were associated with clinical success (102). No correlation between posaconazole serum levels and toxicity was observed. The inability of posaconazole to reach high serum concentrations likely explains this lack of association.

Evidence defining a role for TDM of extended-spectrum triazoles in predicting efficacy is emerging. A recent randomized controlled trial examining the value of TDM with voriconazole in treatment of IFI has been reported (6). Patients with proven or probable IFI (110 patients) were randomly assigned to TDM or non-TDM groups. In the TDM group, dose was adjusted on day 4, targeting a voriconazole blood level of $1.0 \mathrm{mg} / \mathrm{L}$ to $5.5 \mathrm{mg} / \mathrm{L}$, while the patients in the standard treatment arm received a fixed dose with no dose adjustment. Assessors were blinded to the TDM results and groups were matched at baseline (including CYP2C19 phenotypes). Global response (complete and partial response) at three months was $57 \%$ in the TDM arm compared with $38 \%(\mathrm{P}=0.04)$ in the fixed-dose arm (6). Overall adverse events were similar in both arms, but there were fewer discontinuations of voriconazole due to adverse events in the TDM arm versus the fixed dose arm (4\% versus $17 \% ; \mathrm{P}=0.02$ ).

Proper weight-based dosing for voriconazole appears to be essential. A population-based PK/PD study of voriconazole in a cohort of 55 patients with IFI (predominantly hematological malignancies) revealed an oral bioavailability of $0.63 \mathrm{mg} / \mathrm{L}$ and large interpatient variability (109). In this study, use of $200 \mathrm{mg}$ twice daily, which is the labelled dose for voriconazole, produced levels $>1.5 \mathrm{mg} / \mathrm{L}$ in only $49 \%$ of patients. By increasing the oral dose to $300 \mathrm{mg}$ twice daily, a level $>1.5 \mathrm{mg} / \mathrm{L}$ was achieved in $68 \%$ of patients (109). The results of this study suggests that weight-based loading and subsequent dosing appears to be necessary to produce sufficient levels.

Evidence for TDM when posaconazole is administered for antifungal prophylaxis is limited. A recent multicentre study of posaconazole TDM was reported from six centres in Australia (110). Among recipients of posaconazole for prophylaxis (72 of 86 patients), breakthrough infections were noted in $12(17 \%)$ patients. A review of these prophylaxis failures noted that the median posaconazole levels were significantly lower compared with subjects without prophylaxis failure (median $0.289 \mathrm{mg} / \mathrm{L}$ versus $0.485 \mathrm{mg} / \mathrm{L}$, respectively). Furthermore, the median drug levels emerged as an independent predictors of failure by logistic regression analysis $(\mathrm{P}<0.05)(110)$. Risk factors associated with subtherapeutic levels of posaconazole in prophylaxis were GVHD, use of proton pump inhibitors, concomitant drug interactions and diarrhea (110).

Currently, there is a lack of clear understanding of the relationships among achievable blood concentrations of posaconazole and its high tissue levels (a function of the lipophilic nature of the drug), and the safety and efficacy profiles. At present, posaconazole TDM appears to be limited to patients with GVHD of the GI tract, severe diarrhea, potential for drug interactions that lower posaconazole levels and those receiving proton pump inhibitors.

Finally, economic analyses in Canada are also necessary to complement the clinical experience with triazole TDM and to help understand the role of TDM in the practice of clinical mycology. The lack of TDM availability in all Canadian centres likely contributes to the variability in clinical outcomes observed across the country.

\section{TARGET POPULATIONS}

\section{Hematology/oncology patients}

The incidence of IFIs in cancer patients has increased in recent years, particularly among patients with acute leukemia and those undergoing HSCT (111). IA occurs in an estimated $10 \%$ to $20 \%$ of HSCT recipients, $10 \%$ of patients with AML and approximately $5 \%$ of patients with acute lymphoblastic leukemia (112). The increase in IFIs is attributed to the use of more intensive chemotherapy, increasing use of alternative donor source of stem cells and T cell-depleted transplants (113). Mortality rates associated with documented IFIs range from $30 \%$ to $60 \%$, and may be higher among patients after HSCT (114).

The importance of triazole antifungal agents in the management of IFIs in patients with hematological malignancies is considerable $(90,95,103,104,115,116)$. As indicated before, inter- and intrapatient drug exposure to azole antifungals is variable. Poor drug exposure may contribute to breakthrough or progression of IFIs (110), and could interfere with the delivery of an effective anticancer management plan through delays or cessation of therapy, resulting in an increase in allcause patient mortality rate $(114,117)$. In addition, multiple chemotherapeutic and IMs are metabolized via the hepatic CYP system pathways; therefore, the azole antifungals have the potential to interact with many of the drugs used in leukemia and HSCT patients, causing additional morbidity (118). In contrast, relatively few drugs alter the concentration of azoles. However, when such interactions occur, the decreased systemic availability of the azole may compromise efficacy. Of particular note are the drugs that alter gastric acidity, which influence the oral absorption of itraconazole and posaconazole, whereas voriconazole absorption is essentially unaffected (119).

Several investigators have observed a relationship between itraconazole exposure and clinical efficacy in patients with hematological cancer. For example, itraconazole serum levels $>0.25 \mathrm{mg} / \mathrm{L}$ have been associated with a higher probability of prophylaxis and treatment success $(85,120,121)$.

The PK relationship of voriconazole exposure and treatment efficacy has also been evaluated. The impact of voriconazole TDM of trough serum levels in the setting of antifungal prophylaxis was 
analyzed in recipients of allogeneic HSCT. Breakthrough candidiasis was associated with levels $<0.5 \mathrm{mg} / \mathrm{L}$ (122). Successful prophylaxis was correlated with levels $>2 \mathrm{mg} / \mathrm{L}$. This relationship is similar to that observed with itraconazole. Voriconazole exposure toxicity has also been observed. Trough levels ranging from $5.5 \mathrm{mg} / \mathrm{L}$ to $>6 \mathrm{mg} / \mathrm{L}$ were associated with elevated liver enzymes and cholestatic hepatopathy (101). However, the ability to unequivocally prove this association has been confounded by coadministration of hepatotoxic chemotherapy or conditioning regimens for HSCT, or by coexisting GVHD (38).

An exposure-efficacy relationship for posaconazole has been analyzed following two prophylaxis trials involving patients with hematological cancer and HSCT patients $(67,105)$. Serum posaconazole levels obtained $0 \mathrm{~h}$ to $16 \mathrm{~h}$ postdosing ranging from $0.9 \mathrm{mg} / \mathrm{L}$ to $1.36 \mathrm{mg} / \mathrm{L}$ have been associated with prophylaxis success in HSCT recipients with GVHD, whereas prophylaxis efficacy among AML patients undergoing chemotherapy appeared to be associated with average serum levels obtained $1 \mathrm{~h}$ to $3 \mathrm{~h}$ postdosing of $0.5 \mathrm{mg} / \mathrm{L}$. However, low numbers of breakthrough fungal infections were observed in both studies. Other investigators have observed posaconazole prophylaxis efficacy against proven and possible IFIs with plasma levels $\geq 0.5 \mathrm{mg} / \mathrm{L}(107,108)$. Based on these observations, a target steady-state plasma level $\geq 0.7 \mathrm{mg} / \mathrm{L}$ has been proposed (106).

A posaconazole exposure to treatment response has also been evaluated in a therapeutic salvage trial of IA predominantly involving patients with hematological malignancies (102). Clinical success was correlated with mean maximum and average posaconazole plasma concentrations of $1.5 \mathrm{mg} / \mathrm{L}$ and $1.2 \mathrm{mg} / \mathrm{L}$, respectively (102). Although recent observations suggest that target organ intratissue or intracellular posaconazole concentrations may be of greater clinical relevance (123), the reported relationships between therapeutic efficacy and drug exposure, as estimated through posaconazole plasma concentrations, suggests a value in systematic therapeutic plasma drug monitoring (108).

Breakthrough infections by resistant or emerging pathogens are now being reported more frequently $(124,125)$. Recurrence of IFIs with further cycles of intensive chemotherapy or HSCT ranges between $11 \%$ and $33 \%(40,118)$. Therefore, it is important to develop strategies to minimize the risk of recurrence or progression of IFI that may arise subsequently among patients with a history of IFI during previous anticancer treatments. TDM may be able to play an important role in optimizing the efficacy of these strategies (120).

In summary, the consequences of inadequate prevention or treatment of IFI can be devastating. Achieving appropriate drug exposure and minimization of drug toxicity with TDM enhances the likelihood of improved outcomes with antifungal treatment in the highly vulnerable hematology/oncology patient population.

\section{Solid organ transplant recipients}

As mentioned above, there are a number of reasons to pursue TDM for azole antifungal agents in the treatment and prophylaxis of IFIs in solid organ transplant (SOT) recipients. Indeed, there are two issues that are paramount in these patients: assurance of adequate serum levels to attain a favourable outcome (there is a direct exposureresponse relationship); and prevention of undesirable adverse effects due to unwanted drug interactions and overexposure. Linked to the former issue is the variability in absorption after oral administration, which is particularly pertinent to certain populations, such as patients with cystic fibrosis who undergo lung transplantation (126). Also linked to the latter issue is the genotypic variation in drug metabolism (CYP2C19 PM versus EM) (126,127), which predisposes certain patients to either increased drug interactions and toxicity (128), or low plasma concentrations (126). Information related to the use of azole antifungal agents commonly used in SOT recipients for the treatment of IFI is reviewed relative to the need for TDM.

Because the azole antifungal agents commonly used for SOT recipients are available for administration in both oral and intravenous forms, and IFI treatment requires prolonged duration of therapy, there is greater potential for variability in attaining appropriate serum concentrations of these antifungal agents and, thus, obstacles to ultimately attaining a successful outcome (response to therapy for an IFI or prevention of an IFI in the case of prophylactic use) and greater potential for adverse events and toxicity. In fact, it has been advocated that trough plasma concentrations of at least $0.5 \mathrm{mg} / \mathrm{L}$ for itraconazole, (129) $1.5 \mathrm{mg} / \mathrm{L}$ (128) or $2.0 \mathrm{mg} / \mathrm{L}$ (130) for voriconazole, and $>0.5 \mathrm{mg} / \mathrm{L}$ for posaconazole (73) are advisable to ensure an adequate exposure-response relationship in SOT recipients. Although an attempt was made to establish such a relationship for itraconazole in heart and lung transplant recipients, excessive variability was noted and no relationship between a specific trough concentration and response was established (129). With regard to voriconazole, a minimum trough plasma concentration of $>1.5 \mathrm{mg} / \mathrm{L}$ has been correlated with successful outcome in treatment/prophylaxis of IFIs in lung and heart transplant recipients (131) as well as critically ill patients, including some SOT recipients in whom a minimum trough plasma concentration of $\geq 1.5 \mathrm{mg} / \mathrm{L}$ was considered to be the benchmark (128). While a minimum trough plasma concentration of $2.0 \mathrm{mg} / \mathrm{L}$ has been linked to successful prophylaxis and treatment in allogeneic HSCT and treatment of IFIs in hematological malignancy (130), this trough concentration cutoff has not been verified in SOT recipients. As mentioned, a minimum plasma trough concentration of posaconazole of $>0.5 \mathrm{mg} / \mathrm{L}$ in heart and lung transplant recipients was associated with positive outcomes in the prophylaxis or treatment of IFIs (73), Unfortunately, data are lacking in this regard relative to renal, liver and pancreas transplant recipients. In addition, it should be acknowledged that an exposure-toxicity relationship has been far less well defined in solid organ transplantation for voriconazole and posaconazole $(130,131)$. Although visual and neurological adverse events may exhibit an exposure-toxicity relationship for voriconazole trough plasma concentrations $>5.5 \mathrm{mg} / \mathrm{L}$ (128), this has not been definitively substantiated in SOT recipients.

Pertinent to SOT recipients and of greatest importance are the drug interactions associated with azole antifungal agents and concomitantly administered IM agents (calcineurin inhibitors [cyclosporine and tacrolimus] and mammalian targets of rapamycin inhibitors [sirolimus and everolimus]). All azoles inhibit CYP3A4 and thus affect the metabolism of cyclosporine, tacrolimus, sirolimus and everolimus. These azoles may also be substrates for and inhibitors of P-gp, thus producing elevated plasma levels of the IMs. However, the effect of the various azoles is not uniform. For example, with cyclosporine, fluconazole inhibition of CYP3A4 is dose dependent, with significant increases in cyclosporine serum levels of two- to threefold occurring with doses of fluconazole $\geq 200 \mathrm{mg} /$ day after one week of therapy with fluconazole $(75,132)$. As for tacrolimus, fluconazole coadministration necessitated a reduction in tacrolimus dose by $40 \%$ to $56 \%$ to maintain comparable trough serum levels $(133,134)$. Prolonged fluconazole treatment also increases sirolimus trough concentration by 3.5 times after seven days (135) and 4.7 times by 22 days of treatment (136).

Itraconazole is 50 -fold more potent at inhibiting the metabolism of cyclosporine than fluconazole. Dose reductions of cyclosporine were required and ranged from $33 \%$ to $84 \%$ in a case series of heart and lung transplant recipients (137) as well as for tacrolimus when coadministered with itraconazole in heart and/or lung transplant patients (138).

A significant drug interaction has been reported between voriconazole and cyclosporine, producing a 1.7-fold increase in the AUC of cyclosporine in a double-blinded, randomized, crossover clinical trial involving renal transplant recipients (78). Once again, a comparable impact of voriconazole on tacrolimus was exhibited $(59,139)$.

Coadministration of voriconazole and sirolimus necessitated a marked reduction in sirolimus dosage by $75 \%$ to $90 \%$ (75) As noted in a case series involving four SOT recipients, sirolimus plasma concentrations were increased by a mean of 9.6-fold in the presence of voriconazole coadministration $(136,140)$.

There has been a paucity of studies performed to assess the impact of posaconazole on concomitant administration of calcineurin inhibitors. In one study evaluating the effect of the coadministration of posaconazole on cyclosporine and tacrolimus serum levels, posaconazole 
necessitated reductions in cyclosporine dosing by $14 \%$ to $29 \%$ in three of four heart transplant recipients to maintain therapeutic cyclosporin plasma levels (141). In the same study, the concurrent administration of posaconazole and tacrolimus in 34 volunteers was assessed and showed a $358 \%$ increase in the AUC of tacrolimus by day 14 . Of note, posaconazole PK was unaffected. In another report evaluating the treatment of IFIs in SOT recipients (kidney, lung, heart and liver transplants), posaconazole produced increased calcineurin inhibitor levels in three of 22 (14\%) patients (142). Furthermore, in a study involving 12 healthy subjects, the coadministration of posaconazole and sirolimus resulted in an increase in sirolimus maximum serum levels by 6.7 times and the AUC by 8.9 times, respectively (143), demonstrating the properties of posaconazole as an inhibitor of CYP3A4 and sirolimus as a substrate of CYP3A4 (144). Dose adjustments for all the azoles and IMs are presented in Table 2.

Another potential drug interaction of note between posaconazole and proton pump inhibitors has recently come to light. Shields et al (73) highlighted the fact that posaconazole median serum trough levels were significantly reduced among heart and lung transplant recipients receiving proton pump inhibitors compared with those not receiving proton pump inhibitors. However, $\mathrm{H}_{2}$ antagonists exerted no influence on posaconazole median trough levels.

Therefore, TDM for azole antifungal agents in SOT recipients would appear to be prudent to achieve adequate trough plasma concentrations for the broad-spectrum azole antifungal agents, particularly voriconazole, with its considerable inter- and intrapatient variability, as well as posaconazole, after initiating therapy once steady-state PK properties have been achieved. TDM is useful when transitioning from intravenous to oral therapy to ensure the adequacy of serum levels of oral therapy due to potential variations in absorption in SOT recipients. This approach, targeting minimum trough plasma concentration of $\geq 1.5 \mathrm{mg} / \mathrm{L}$ for voriconazole and $>0.5 \mathrm{mg} / \mathrm{L}$ for posaconazole, should consistently provide successful outcomes in both the prophylaxis and treatment of IFIs in SOT recipients. As well, maintaining voriconazole trough plasma concentrations $\leq 5.5 \mathrm{mg} / \mathrm{L}$ may avoid visual and neurological adverse events in SOT recipients. Moreover, recognition of the important drug interactions between the azole antifungal IM agents and proton pump inhibitors is advantageous to enable anticipatory adjustment in the IM dosages to avoid unwanted toxicities in SOT patients.

\section{Pediatric patients}

Several arguments support a role for TDM in the management of pediatric patients receiving selected azole-based antifungal therapy: the PKs of drugs differ considerably with age (from newborns to adolescents), which results in variable drug exposures, and differential efficacy and toxicity profiles that require different dosing; drug dosages in pediatric patients are commonly based on extrapolations from adult data; PK data from children with underlying medical conditions are rare; and oral formulations are typically administered using a nasogastric tube. All of these considerations are supportive of the use of TDM in the pediatric population.

Several studies have shown a direct correlation between fluconazole exposure, in vitro susceptibility and the response to treatment (145-147). However, TDM appears to be unnecessary given the broad fluconazole therapeutic index and the lack of relationship between PK data and toxicity $(11,148-150)$.

As in adults, the itraconazole PK parameters obtained using the capsule formulation are substantially inferior to those obtained using the suspension. The AUC is at least 30\% smaller, on average, than that observed with the suspension, and the maximum steady-state concentration after capsule dosing is almost 50\% less than that observed with the suspension (19). These differences are the direct result of the differences in absorption between the two oral formulations, which are influenced by diet and gastric $\mathrm{pH}(17,20)$. In addition, the studies conducted in immunocompromised patients found even lower values and even greater variability in these parameters $(151,152)$.

Itraconazole is metabolized into a large number of metabolites. Hydroxy-itraconazole (OH-ITZ) is the main metabolite, with plasma concentrations 1.5- to twofold higher than those of itraconazole. In addition, it has antifungal properties comparable with those of itraconazole $(153,154)$.

A correlation between concentration and efficacy has been demonstrated in animal models (155) and clinical studies, both for prophylactic $(84,156)$ and directed $(120,157)$ therapy.

The considerable interindividual variability, which is formulation dependent, and the paucity of pediatric data are arguments for proposing the use of itraconazole TDM in children, especially because the recommended dosages appear to be too low (158). Systematic monitoring of itraconazole concentrations appears to be of greatest use in the most vulnerable patients (congenital or acquired immune deficiency) $(158,159)$. However, caution is advocated in the interpretation of levels due to limitations in the analytical methods used to measure bioactive parent compound and metabolites of itraconazole.

Although voriconazole is officially approved only for use in patients $\geq 12$ years of age in Canada, it has been used in younger children, including newborns (160-162). The variability in pediatric serum concentrations appears to be even greater than the variability observed in the adult population (163-165). For example, voriconazole is metabolized to the inactive $\mathrm{N}$-oxide voriconazole (NO-VRC) product more quickly in children. This can be explained by several factors: flavin-containing monooxygenase 3 , which plays an important role in voriconazole metabolism, is more active in children than in adults (166); and CYP2C19 plays a greater role in voriconazole metabolism in children than in adults (166). N-oxidation by these two pathways is three- to fivefold greater in children than in adults, while $\mathrm{N}$-oxidation by CYP3A4 is similar between children and adults. In addition, the metabolism of voriconazole by CYP2C19 is subject to the influence of different factors, such as the patient's genetics $(51,167)$, age and inflammatory status $(168,169)$, drug interactions (170) and hepatic function.

The correlation between voriconazole exposure and clinical efficacy is usually measured by the PK/PD efficacy parameter, the $\mathrm{AUC}_{0-24 \mathrm{~h}}$ :MIC ratio, as reported in both in vitro and animal models (171). Such correlations have been made in clinical studies. However, a systematic calculation of the $\mathrm{AUC}_{0-24 \mathrm{~h}}$ is difficult to perform in children because of the large number of specimens required and the associated blood loss (172). Other studies have reported an association between clinical efficacy in patients with proven or probable IFIs and residual trough serum concentrations (predose), a manifestation of drug exposure time above the MIC for a given pathogen $(\mathrm{T}>\mathrm{MIC})$ $(42,97,99,122,173,174)$. A retrospective study of voriconazole measurements in 46 patients by Neely et al (175) reported an association between trough concentrations $>1 \mathrm{mg} / \mathrm{L}$ and survival. The mortality rate was $28 \%$, and each residual serum voriconazole concentration $<1 \mathrm{mg} / \mathrm{L}$ was associated with a 2.6-fold increase in the risk of death ( $95 \%$ CI 1.6 to 4.8 ). Accordingly, the measurement of this value may be more feasible for current pediatric practice.

In addition, other studies have reported the existence of a concentration-toxicity relationship with voriconazole. The first adverse effects to be associated with a high concentration were visual disturbances followed by liver function and neurological abnormalities (97,173,176-179).

The PKs of voriconazole in children are unique and are characterized by a linear elimination. At adult standard doses $(4 \mathrm{mg} / \mathrm{kg}$ every $12 \mathrm{~h}$ ), serum levels of voriconazole are approximately threefold lower in children (180). The bioavailability in children ranges from $66 \%$ to $80 \%(175,181)$, approximately $17 \%$ to $31 \%$ lower than the $90 \%$ reported for adults. Given these observations, higher dosing regimens $(8 \mathrm{mg} / \mathrm{kg} /$ dose every $12 \mathrm{~h}$ ) of voriconazole have been recommended for children to achieve a serum concentration of $>1 \mathrm{mg} / \mathrm{L}$.

The lack of a duly defined pediatric dosage, the considerable PK variability, the importance of quickly achieving effective concentrations, the narrow therapeutic index and the inability to assess clinical efficacy quickly indicate the prudent use of systematic voriconazole TDM in pediatric patients $(6,164,172,175,182,183)$. 
Posaconazole is approved only in children $>13$ years of age. Limited data are available regarding posaconazole's PKs in younger children (184).

The important considerations for posaconazole TDM in children include the interindividual variability, which depends on absorption; the paucity of available pediatric data; the impact on the PK of nasogastric administration of posaconazole in sick children (185); and the need to have the most effective treatment possible for IFIs in vulnerable immunocompromised children. These considerations all support the use of posaconazole TDM in children.

In summary, the paucity of pediatric PK data has made dose-response predictions unreliable. Moreover, the interindividual variability in serum concentration, the potential availability of measurements of azole levels in real time in routine hospital laboratories, the difficulties in the definition of PK/PD efficacy parameters in pediatric populations and the need for these agents to quickly be effective for managing IFIs in vulnerable immunocompromised children are all strong arguments for pursuing azole TDM in pediatric patients.

\section{LABORATORY METHODS}

The laboratory practice of azole TDM must consider whether the measurements should be limited to the parent drug only or inclusive of metabolites and other related substances.

\section{Substances to consider for monitoring}

Fluconazole: Approximately $65 \%$ to $90 \%$ of fluconazole, the only water-soluble antifungal, is excreted unchanged in the urine $(10,186,187)$. Two metabolites (a glucuronide conjugate of fluconazole and fluconazole $\mathrm{N}$-oxide) are found in small quantities $(<10 \%)$ in the urine. Neither possesses antifungal activity. Consequently, measurement of the parent portion only is sufficient for monitoring fluconazole.

Itraconazole: Itraconazole is sequentially biotransformed by the liver isoenzyme CYP3A4 into OH-ITZ, and then into keto-itraconazole and $\mathrm{N}$-desalkyl-itraconazole $(15,27,188)$. OH-ITZ is present in the plasma at concentrations at least equal to and generally greater than those of itraconazole $(23,189-194)$. OH-ITZ possesses antifungal properties and activity similar to itraconazole (195). Its concentration should be measured as part of itraconazole TDM (23). Different active stereoisomers are present in the commercial form of itraconazole (Sporanox; Janssen Pharmaceutica, Belgium) and appear to be biotransformed unequally by CYP3A4 (196). Itraconazole TDM should, therefore, provide the level of each compound that contributes to any antifungal activity or at least provide the sum of these levels in terms of itraconazole parent-form equivalence.

Voriconazole: Voriconazole is biotransformed mainly by the hepatic isoenzymes CYP2C19 and CYP3A4, and flavin mono-oxygenase to NO-VRC $(47,166,197)$. NO-VRC does not have any antifungal activity (198); however, its plasma concentration can vary considerably $(50,199-201)$. It has been suggested that a determination of the NO-VRC/voriconazole ratio may provide information about a patient's metabolic phenotype and may play a role in voriconazoleassociated hepatotoxicity and phototoxicity $(199,202-206)$. It is, therefore, desirable to measure the NO-VRC concentration in addition to that of voriconazole.

Posaconazole: Posaconazole is mainly eliminated unchanged in the feces. A smaller quantity is also eliminated in the urine $(207,208)$, mostly in the form of three different glucuronide derivatives that appear to exhibit no antifungal activity. Thus, monitoring should be limited to measuring only the parent compound.

\section{Analytical techniques}

Bioassays or microbiological assays, and instrumental techniques are the two main categories of method used to measure the concentration of antifungal antibiotics. Bioassays can determine the total antifungal activity of a drug, but cannot quantify the individual concentrations of the various components or metabolites of that drug. Conversely, instrumental techniques, such as high-performance liquid chromatography
(HPLC) or ultra-HPLC, can quantify individual concentrations of different components of a drug but cannot assess its activity.

\section{Bioassays}

Bioassays are inexpensive, and require limited equipment and personnel training. They are relatively simple and require less technician time than HPLC. However, the turnaround time for results is much longer. Bioassay results are usually available after $20 \mathrm{~h}$ to $24 \mathrm{~h}$ compared with $3 \mathrm{~h}$ to $4 \mathrm{~h}$ for a chromatographic technique. Some bioassays require a sample of only a few tens of microlitres, while certain chromatographic techniques require a few hundred microlitres. The sensitivity of bioassays varies widely among laboratories and, for any given antifungal, depends mainly on the microorganism used as the marker. The range of concentrations measured by bioassay is narrower than when measured with HPLC. The clinical importance of this limitation is relative. For example, when a target therapeutic threshold serum concentration is set at $1 \mathrm{mg} / \mathrm{L}$, the significance of measuring levels by instrumental means to as low as $0.1 \mathrm{mg} / \mathrm{L}$ is negligible.

Diffusion of the body fluid in the agar medium is a critical element in bioassays. Regardless of whether the fluid is transferred onto filter paper and subsequently placed on an agar plate, or inoculated directly into a well of an agar plate, the variable physical diffusion capacity of the drug can yield imprecise inhibition zones and, hence, imprecise drug concentrations. Monitoring drug levels in patients on combination therapy is a major limitation of bioassays. In general, fungal isolates selected as markers (mainly Candida species) are susceptible to multiple antifungal agents. The use of strains that are susceptible to the antifungal of interest but resistant to the others may minimize this limitation; however, such strains are not readily available.

Correlation between bioassay and chromatographic techniques for most triazoles is usually very good (209-215). Itraconazole bioassays, however, show much higher concentrations in patient serum samples than those measured with HPLC. Absence of an OH-ITZ analytical standard for the HPLC measurement was believed to be the reason $(216,217)$. However, bioassay results remain higher even when combined ITZ and OH-ITZ concentrations are measured by HPLC $(27,218-221)$. The total itraconazole concentration (itraconazole + $\mathrm{OH}-\mathrm{ITZ}$ ) in various patients, as measured by bioassay, may be four to six times higher than the concentration of itraconazole alone as measured by HPLC. A collaborative study among five experienced, independent laboratories showed that a correction factor of 1.04 to 5.1 and 0.26 to 2.12 had to be applied if OH-ITZ and itraconazole are used as standards, respectively (220-222). Poor solubility of itraconazole in water and limited diffusion in the aqueous environment of agar gel may cause smaller zones of itraconazole in spiked standards, causing overestimation of drug concentration in blood samples (221). It is difficult to conduct TDM of itraconazole and OH-ITZ based on the concentrations obtained by bioassay. Accordingly, this relegates the measurement of itraconazole by bioassay to a semiquantitative measurement test at best (195).

\section{Instrumental techniques}

A considerable number of electrophoretic and chromatographic techniques and methods have been described to measure fluconazole, itraconazole, voriconazole and posaconazole levels in body fluids and tissues (223).

HPLC/ultra-HPLC techniques have become the reference methods for antifungal antibiotic measurements. These techniques are based on detection by spectrophotometry or absorbance and mass spectrometry. Interest in mass spectrometry has increased recently. Mass spectrometry can be used to measure several azole antifungal agents simultaneously, even when combined with echinocandins $(224,225)$. Optical techniques are more accessible and are still used in a considerable number of clinical laboratories (226). During the second round of testing in 2012 by the International Interlaboratory Quality Control Program for Antifungal Drugs, set up by Brüggemann et al (226) (www.kkgt.nl), optical and mass spectrometry-based techniques were used at similar rates by the participating laboratories 


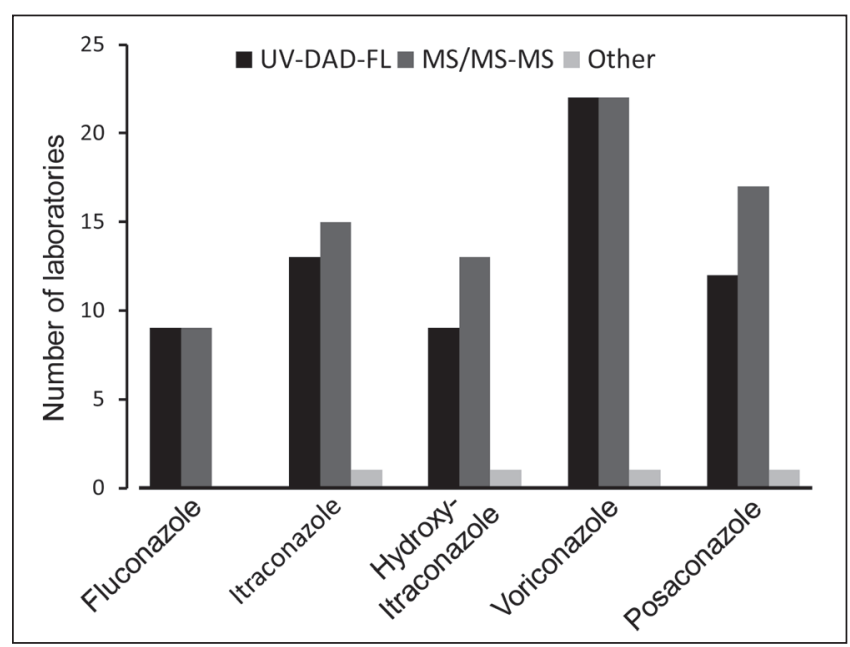

Figure 1) Number of laboratories, among the 57 that participated in the second round of the International Interlaboratory Quality Control Program for Antifungal Drugs in 2012, that used liquid chromatography techniques coupled to either ultraviolet/diode array/fluorescence (UV-DAD-FL) or mass spectrometry/tandem mass spectrometry (MS/MS-MS) detectors for quantification of azole antifungal. From: International Interlaboratory Quality Control Program for Antifungal Drugs, Second Round 2012. Theoret Y, Personnal Communication

(Figure 1). Despite the increasing interest in mass spectrophotometry, developments and improvements in optical techniques continue to be reported $(227,228)$.

Other techniques, such as micellar electrokinetic chromatography, are also used. However, reproducibility has been more difficult to achieve than for the HPLC techniques, and this greatly limits clinical utility of micellar electrokinetic chromatography techniques (196,229-233).

Although gas-phase chromatography instruments are widely used in clinical laboratories, methods to measure antifungal agents have not been widely developed.

Considerations when choosing an analytical method

The development of an analytical method for antifungal TDM will be influenced, from an instrumental standpoint, by the characteristics (or limitations) of each component of a liquid-phase chromatographic system and the ability of spectrophotometric detectors to detect interference from other compounds that could elute at the same retention time as the azoles. This is especially important because the wavelengths used for most spectrophotometric techniques for azole antifungals are in the low ultraviolet spectrum (210 nm to $260 \mathrm{~nm}$ ), a range frequently 'contaminated' with other interfering substances (234) Clinical considerations should also include the nature of the antifungals (and their metabolites) to be measured, the nature of biological sample that will be submitted (eg, plasma, serum, cerebrospinal fluid or blood on blotting paper), how often the determinations will be required, and the desired analytical sensitivity (ie, measurement of the total concentration or of only the free active fraction). These different clinical and instrumental variables will guide the choice of chromatographic column and how the sample will be processed (eg, protein precipitation and solid- or liquid-phase extraction). Personnel expertise (theoretical and practical) in chromatographic techniques and the availability of trained technical support for maintaining and repairing the equipment are other considerations that need to be taken into account. Finally, the development of an analytical method for antifungal TDM should include validation of the analytical method in accordance with established standards $(235,236)$.

In conclusion, measurements of triazoles concentrations in body fluids are easily accessible to most clinical laboratories by bioassay (except for itraconazole) or by chromatographic techniques already established at the centre.

\section{PRACTICAL CONSIDERATIONS}

Level of evidence

The goal of any antimicrobial therapy is to achieve favourable clinical and microbiological outcomes, and avoid drug-associated toxicity (237). Numerous observations have underscored the unpredictable dose-exposure relationship of several triazole antifungal antibiotics and attempts have been made to associate clinical outcome and toxicities to serum levels $(15,41,70,238,239)$. Our understanding of the PD relationship of triazole plasma levels and efficacy or toxicity remains poor. The relationship between drug levels and clinical response or toxicity is difficult to establish because of the confounding effects of comorbidities and host immune function. Therefore, recommendations regarding the optimal use of TDM for itraconazole, voriconazole and posaconazole are based on levels of evidence that are likely to change as more definitive data become available.

\section{RECOMMENDATIONS}

When should triazole plasma levels be ordered?

- Triazole TDM should be considered when the anticipated duration of treatment is $\geq 1$ week. (Weak recommendation, low quality of evidence)

- TDM should be considered in the majority of patients receiving itraconazole. (Strong recommendation, moderate quality of evidence)

- Levels of voriconazole should be monitored irrespective of formulation and determined no sooner than after three to five days of administration. (Strong recommendation, high quality of evidence)

- Monitoring of posaconazole should be considered when a nasogastric administration route is used or when coadministration of proton pump inhibitors is used. (Weak recommendation, moderate quality of evidence)

- Levels of itraconazole and posaconazole should be determined after seven days of administration due to their prolonged half-lives. (Strong recommendation, high quality of evidence)

- Monitoring of itraconazole, voriconazole and posaconazole may be deemed necessary in pediatric patients due to low serum levels commonly observed following standard recommended dosing. (Weak recommendation, moderate quality of evidence)

When should trough plasma levels be measured?

- Trough levels should be measured within 30 min before patient dosing. (Weak recommendation, moderate quality of evidence)

Which clinical conditions are appropriate for plasma level monitoring of triazole antifungal agents?

- Circumstances of suspected signs of toxicity not otherwise explained and presumably associated with high drug exposure. (Strong recommendation, moderate quality of evidence)

- Circumstances of poor clinical response not otherwise explained or anticipated, and presumably associated to suboptimal drug exposure. (Weak recommendation, moderate quality of evidence)

- Circumstances involving a risk for drug-drug interactions that could modify the agent's usual PK properties and impact efficacy or toxicity. (Weak recommendation, low quality of evidence)

- Conditions conducive to poor drug exposure due to triazole antifungal agent formulation or questionable oral absorption due to impaired GI integrity (eg, presence of diarrhea, mucositis, intestinal GVHD) or suspicion of poor compliance to therapy. (Weak recommendation, low quality of evidence)

- In cystic fibrosis patients and in lung transplant recipients during the early 30-day post-transplant period to individualize voriconazole dosage. (Weak recommendation, high quality of evidence) 
What trough plasma level values should be targeted (Table 4)?

TABLE 4

Recommended target trough plasma levels

\begin{tabular}{lllcc}
\hline \multirow{2}{*}{ Agent } & \multicolumn{2}{c}{ Efficacy } & Safety & Recommendation, \\
\cline { 2 - 5 } Fluconazole & $\begin{array}{l}\text { Prophylaxis } \\
\text { Plasma level }\end{array}$ & Treatment & Toxicity & level of evidence \\
\hline & $\begin{array}{l}\text { monitoring } \\
\text { rarely needed }\end{array}$ & & Strong, High \\
Itraconazole & $\geq 0.5 \mathrm{mg} / \mathrm{L}$ & $1.0-2.0 \mathrm{mg} / \mathrm{L}$ & $\mathrm{NA}$ & Weak, Moderate \\
Voriconazole & $\geq 0.5 \mathrm{mg} / \mathrm{L}$ & $1.5-5.0 \mathrm{mg} / \mathrm{L}$ & $<5.5 \mathrm{mg} / \mathrm{L}$ & Weak, Moderate \\
Posaconazole & $\geq 0.7 \mathrm{mg} / \mathrm{L}$ & $1.0-1.5 \mathrm{mg} / \mathrm{L}$ & $\mathrm{NA}$ & Weak, Very low \\
\hline
\end{tabular}

NA Not applicable because of lack of data

Should plasma levels be monitored following change in formulation and/or dosage?

- Following sequential parenteral-to-oral therapy, plasma levels should be monitored to confirm adequate drug exposure. (Weak recommendation, low quality of evidence)

- Following dosage adjustment, repeat monitoring should be ordered when steady state of the antifungal agent is obtained. (Weak recommendation, low quality of evidence)

What are the suggested triazole dose adjustment strategies for patients treated for IFIs (Table 5)?

TABLE 5

Suggested triazole dose adjustment strategies for patients treated for invasive fungal infections

\begin{tabular}{|c|c|c|c|}
\hline Agent & $\begin{array}{c}\text { Measured level, } \\
\mathrm{mg} / \mathrm{L}\end{array}$ & Dose adjustment & $\begin{array}{l}\text { Recommendation, } \\
\text { level of evidence }\end{array}$ \\
\hline \multirow[t]{3}{*}{ Itraconazole } & $<0.25$ & Increase by $50 \%$ & Weak, Very low \\
\hline & $\geq 0.25-1.0$ & Increase by $25 \%$ & Weak, Very low \\
\hline & $\begin{array}{l}>1.0 \text { and drug- } \\
\text { related } \\
\text { toxicities }\end{array}$ & Reduce by $50 \%$ & Weak, Very low \\
\hline \multirow[t]{4}{*}{ Voriconazole } & $<0.5$ & Increase by $50 \%$ & Weak, Low \\
\hline & $\geq 0.5-<1.5$ & Increase by $25 \%$ & Weak, Low \\
\hline & $\geq 1.5-<5.5$ & None & Weak, Low \\
\hline & $\begin{array}{l}\geq 5.5 \text { and } \\
\text { drug-related } \\
\text { toxicities }\end{array}$ & Decrease by $25 \%$ & Weak, Low \\
\hline Posaconazole & $<1.5$ & Increase by $30 \%$ * & Weak, Very low \\
\hline
\end{tabular}

${ }^{*}$ Additional strategies to consider: administer with high-fat food; take with acidic drinks; remove acid suppressants; split the dose to $200 \mathrm{mg}$ four times per day versus $400 \mathrm{mg}$ twice daily

When should plasma levels be repeated?

- Any change in the patient clinical condition that could affect the $\mathrm{PK} / \mathrm{PD}$ of the administered triazole should prompt a repeat monitoring when steady state is achieved. (Weak recommendation, very low quality of evidence)

\section{CONCLUSIONS}

Although many patient factors, such as the underlying disease, bone marrow function, nonmyeloid organ dysfunction, performance status, concomitant use of IMs, drug-drug interactions, nutritional status, genetic polymorphisms and host immune status, play an important role in the overall outcome for patients with IFI, the ability to maintain an adequate therapeutic serum concentration of antifungal agents may also be critical. Prospective studies are needed to validate the clinical utility of triazole antifungal agents TDM and to clarify its role in the standard of care of patients.
ACKNOWLEDGEMENT: CME Solutions Canada provided secretarial assistance to integrate the references that were listed in the various draft sections initially written by each coauthor. CME Solutions Canada assistance was supported by Pfizer Canada Inc. The role of CME Solutions Canada and Pfizer Canada Inc. was strictly limited to the assistance listed above. Neither organization was involved in the writing and iteration of the various versions of the manuscript. All authors substantially contributed to the creation of this publication.

DISCLOSURES: Michel Laverdiere had received paid consultancy fees from Astellas Pharma Canada, Merck Canada Inc and Pfizer Canada, and speaker fees from Astellas Pharma Canada, Merck Canada Inc and Pfizer Canada. Eric Bow has been a consultant for and received research funding from Merck-Frosst, Astellas Pharma Canada and Pfizer Canada. Coleman Rotstein has been paid consultant fees and speaker honoraria from Astellas Pharma Canada Inc, Merck Canada Inc and Pfizer Canada, and received research grant support from Astellas Pharma Canada Inc, Merck Canada Inc and Pfizer Canada. Julie Autmizguine has no potential conflicts of interest to declare. Raewyn Broady has received paid consultancy fees from Pfizer Canada. Gary Garber has received paid consultancy fees from Merck Canada Inc and Pfizer Canada. Shariq Haider had received paid consultancy fees from Astellas Pharma Canada Inc, Merck Canada Inc and Pfizer Canada, as well as research grant support from Merck Canada Inc and Pfizer Canada. Trana Hussaini has no potential conflicts of interest to declare. Shahid Husain has been paid consultant fees from Merck Canada Inc and Pfizer Canada and has received research grant support from Astellas Pharma Canada Inc, Merck Canada Inc and Pfizer Canada. Philippe Ovetchkine has no potential conflicts of interest to declare. Jack T Seki has received honoraria as consultant and speaker from Astellas Pharma Canada Inc, Merck Canada Inc and Pfizer Canada, and study grants from Amgen, Astellas Pharma Canada Inc, Pfizer Canada, Merck Canada Inc and Sanofi. Yves Théorêt has no potential conflicts of interest to declare.

\section{APPENDIX 1 \\ SOURCES, METHODOLOGY AND MESH TERMS USED IN THE LITERATURE REVIEW \\ Sources}

- Medline 1946 to 2013, Embase 1974 to 2012 September 12, Biosis, CAB Abstracts

Limits

- English Only, Human

Key words

- (Fungal adj3 infection) and (hematol adj2 oncology) or (acute adj2 leukemia) or (bone adj2 marrow adj2 transplant)

- (Plasma adj2 cc) and (efficacy or toxicity)

- (antifungal adj2 (drug adj2 interaction)

- (biotransformation or $\mathrm{N}$-oxide or genetic polymorphism or CYP3A4).

- (front adj2 loading)

- (Fungistatic and fungicidal)

- (High Performance Liquid Chromatography or HPLC)

- (internal standard or (certificate adj2 analysis))

- (kinetic adj1 model)

- (nonlinear and Michaelis-Menten and pharmacokinetics).

- (Paediatric or pediatric) and (Toxicity or level or monitor)

- (plasma and (efficacy or toxicity))

- (plasma or saliva) adj3 concentration)

- (saturation adj3 metabolism)

- (slow or rapid) adj2 metabolizer

- (Solid organ transplant or Lung transplant)

- (species-specific and time-kill)

- (therapeutic adj3 level) or (serum adj3 level)

- (therapeutic adj3 level) or (serum adj3 level)

- (time adj2 kill) and (studies or study or trial)

- (Trough adj2 level) or (random adj2 Level) or (hepatic adj2 toxicity) or (visual adj2 disturbance) 


\section{APPENDIX 1 - CONTINUED}

- (Fluconazole, Itraconazole, Voriconazole. Posaconazole and monitoring or level

- bioassay

- blot paper

- CYP2C19 protein

- CYP2C19 protein

- dose or dosing or dosage or quantit

- dose or dosing or dosage or quantit

- front adj2 loading

- mass spectrometry

\section{REFERENCES}

1. Azie N, Neofytos D, Pfaller M, Meier-Kriesche HU, Quan SP, Horn D. The PATH (Prospective Antifungal Therapy) Alliance ${ }^{\circledR}$ registry and invasive fungal infections: Update 2012. Diagn Microbiol Infect Dis 2012;73:293-300.

2. Rybak M, Lomaestro B, Rotschafer JC, et al. Therapeutic monitoring of vancomycin in adult patients: A consensus review of the American Society of Health-System Pharmacists, the Infectious Diseases Society of America, and the Society of Infectious Diseases Pharmacists. Am J Health Syst Pharm 2009;66:82-98.

3. Bartal C, Danon A, Schlaeffer F, et al. Pharmacokinetic dosing of aminoglycosides: A controlled trial. Am J Med 2003;114:194-8.

4. Scaglione F, Esposito S, Leone S, et al. Feedback dose alteration significantly affects probability of pathogen eradication in nosocomial pneumonia. Eur Respir J 2009;34:394-400.

5. Haider S, Rotstein C, Horn D, Laverdiere M, Azie N. The Prospective Antifungal Therapy Alliance ${ }^{\circledR}$ registry: A two-centre Canadian experience. Can J Infect Dis Med Microbiol 2014;25:17-23.

6. Park WB, Kim NH, Kim KH, et al. The effect of therapeutic drug monitoring on safety and efficacy of voriconazole in invasive fungal infections: A randomized controlled trial. Clin Infect Dis 2012;55:1080-7.

7. Guyatt GH, Oxman AD, Kunz R, et al. Going from evidence to recommendations. BMJ 2008;336:1049-51.

8. Guyatt GH, Oxman AD, Kunz R, et al. What is "quality of evidence" and why is it important to clinicians? BMJ 2008;336:995-8.

9. Guyatt GH, Oxman AD, Vist GE, et al. GRADE: An emerging consensus on rating quality of evidence and strength of recommendations. BMJ 2008;336:924-6.

10. Diflucan ${ }^{\circledR}$ (fluconazole) [package insert]. Kirkland, Quebec: Pfizer Canada, Inc; 2012.

11. Brammer KW, Farrow PR, Faulkner JK. Pharmacokinetics and tissue penetration of fluconazole in humans. Rev Infect Dis 1990;12(Suppl 3):S318-26.

12. Milliken S, Helenglass G, Powles R. Fluconazole pharmacokinetics following oral dosage in leukaemic patients receiving autologous bone marrow transplantation. Bone Marrow Transplant 1988;3(Suppl 1):324-5.

13. Wildfeuer A, Laufen H, Schmalreck AF, Yeates RA, Zimmermann T. Fluconazole: Comparison of pharmacokinetics, therapy and in vitro susceptibility. Mycoses 1997;40:259-65.

14. Berl T, Wilner KD, Gardner M, et al. Pharmacokinetics of fluconazole in renal failure. J Am Soc Nephrol 1995;6:242-7.

15. Poirier JM, Cheymol G. Optimisation of itraconazole therapy using target drug concentrations. Clin Pharmacokinet 1998;35:461-73.

16. Bae SK, Park SJ, Shim EJ, et al. Increased oral bioavailability of itraconazole and its active metabolite, 7-hydroxyitraconazole, when coadministered with a vitamin $\mathrm{C}$ beverage in healthy participants. J Clin Pharmacol 2011;51:444-51.

17. Jaruratanasirikul S, Kleepkaew A. Influence of an acidic beverage (Coca-Cola) on the absorption of itraconazole. Eur J Clin Pharmacol 1997;52:235-7.

18. Van Peer A, Woestenborghs R, Heykants J, Gasparini R, Gauwenbergh G. The effects of food and dose on the oral systemic availability of itraconazole in healthy subjects. Eur J Clin Pharmacol 1989;36:423-6.

19. Barone JA, Moskovitz BL, Guarnieri J, et al. Enhanced bioavailability of itraconazole in hydroxypropyl-beta-cyclodextrin solution versus capsules in healthy volunteers. Antimicrob Agents Chemother 1998;42:1862-5.
- metabolism

- pharmacodynamics

- pharmacokinetic or PK

- pharmacokinetics

- population pharmacokinetics

- proficiency testing

- risk adj2 benefit

- risk adj2 benefit

- SIRS

- therapeutic drug monitoring or tdm

- therapeutic adj2 drug adj2 monitor or tdm

20. Van de Velde VJ, Van Peer AP, Heykants JJ, et al. Effect of food on the pharmacokinetics of a new hydroxypropyl-beta-cyclodextrin formulation of itraconazole. Pharmacotherapy 1996;16:424-8.

21. Hall SD, Thummel KE, Watkins PB, et al. Molecular and physical mechanisms of first-pass extraction. Drug Metab Dispos 1999;27:161-6.

22. Tapaninen T, Backman JT, Kurkinen KJ, Neuvonen PJ, Niemi M. Itraconazole, a P-glycoprotein and CYP3A4 inhibitor, markedly raises the plasma concentrations and enhances the renin-inhibiting effect of aliskiren. J Clin Pharmacol 2011;51:359-67.

23. Templeton IE, Thummel KE, Kharasch ED, et al. Contribution of itraconazole metabolites to inhibition of CYP3A4 in vivo. Clin Pharmacol Ther 2008;83:77-85.

24. Poirier JM, Berlioz F, Isnard F, Cheymol G. Marked intra- and interpatient variability of itraconazole steady state plasma concentrations. Therapie 1996;51:163-7.

25. Stevens DA. Itraconazole in cyclodextrin solution. Pharmacotherapy 1999;19:603-11.

26. Harousseau JL, Dekker AW, Stamatoullas-Bastard A, et al. Itraconazole oral solution for primary prophylaxis of fungal infections in patients with hematological malignancy and profound neutropenia: a randomized, double-blind, double-placebo, multicenter trial comparing itraconazole and amphotericin B. Antimicrob Agents Chemother 2000;44:1887-93.

27. Heykants J, Van Peer A, Van de Velde V, et al. The clinical pharmacokinetics of itraconazole: An overview. Mycoses 1989;32(Suppl 1):67-87.

28. Ahmad SR, Singer SJ, Leissa BG. Congestive heart failure associated with itraconazole. Lancet 2001;357:1766-7.

29. Hope WW, Billaud EM, Lestner J, Denning DW. Therapeutic drug monitoring for triazoles. Curr Opin Infect Dis 2008;21:580-6.

30. Jeu L, Piacenti FJ, Lyakhovetskiy AG, Fung HB. Voriconazole. Clin Ther 2003;25:1321-81.

31. Koltin Y, Hitchcock CA. The search for new triazole antifungal agents. Curr Opin Chem Biol 1997;1:176-82.

32. Lortholary $\mathrm{O}$, Obenga $\mathrm{G}$, Biswas $\mathrm{P}$, et al. International retrospective analysis of 73 cases of invasive fusariosis treated with voriconazole. Antimicrob Agents Chemother 2010;54:4446-50.

33. Perfect JR, Marr KA, Walsh TJ, et al. Voriconazole treatment for less-common, emerging, or refractory fungal infections. Clin Infect Dis 2003;36:1122-31.

34. Troke P, Aguirrebengoa K, Arteaga C, et al. Treatment of scedosporiosis with voriconazole: Clinical experience with 107 patients. Antimicrob Agents Chemother 2008;52:1743-50.

35. Leveque D, Nivoix Y, Jehl F, Herbrecht R. Clinical pharmacokinetics of voriconazole. Int J Antimicrob Agents 2006;27:274-84.

36. Purkins L, Wood N, Greenhalgh K, Eve MD, Oliver SD, Nichols D. The pharmacokinetics and safety of intravenous voriconazole a novel wide-spectrum antifungal agent. Br J Clin Pharmacol 2003;56(Suppl 1):2-9.

37. Lazarus HM, Blumer JL, Yanovich S, Schlamm H, Romero A. Safety and pharmacokinetics of oral voriconazole in patients at risk of fungal infection: A dose escalation study. J Clin Pharmacol 2002;42:395-402.

38. Trifilio S, Ortiz R, Pennick G, et al. Voriconazole therapeutic drug monitoring in allogeneic hematopoietic stem cell transplant recipients. Bone Marrow Transplant 2005;35:509-13.

39. Purkins L, Wood N, Kleinermans D, Greenhalgh K, Nichols D. Effect of food on the pharmacokinetics of multiple-dose oral voriconazole. Br J Clin Pharmacol 2003;56(Suppl 1):17-23. 
40. Choi SH, Lee SY, Hwang JY, et al. Importance of voriconazole therapeutic drug monitoring in pediatric cancer patients with invasive aspergillosis. Pediatr Blood Cancer 2013;60:82-7.

41. Denning DW, Ribaud P, Milpied N, et al. Efficacy and safety of voriconazole in the treatment of acute invasive aspergillosis. Clin Infect Dis 2002;34:563-71.

42. Miyakis S, van Hal SJ, Ray J, Marriott D. Voriconazole concentrations and outcome of invasive fungal infections. Clin Microbiol Infect 2010;16:927-33.

43. Sim SC, Risinger C, Dahl ML, et al. A common novel CYP2C19 gene variant causes ultrarapid drug metabolism relevant for the drug response to proton pump inhibitors and antidepressants. Clin Pharmacol Ther 2006;79:103-13.

44. Trifilio SM, Yarnold PR, Scheetz MH, Pi J, Pennick G, Mehta J. Serial plasma voriconazole concentrations after allogeneic hematopoietic stem cell transplantation. Antimicrob Agents Chemother 2009;53:1793-6.

45. Vfend ${ }^{\circledR}$ (voriconazole) [package insert]. New York: Pfizer, Inc; 2011.

46. Pai MP, Lodise TP. Steady-state plasma pharmacokinetics of oral voriconazole in obese adults. Antimicrob Agents Chemother 2011;55:2601-5.

47. Hyland R, Jones BC, Smith DA. Identification of the cytochrome $\mathrm{P} 450$ enzymes involved in the $\mathrm{N}$-oxidation of voriconazole. Drug Metab Dispos 2003;31:540-7.

48. Blaisdell J, Mohrenweiser H, Jackson J, et al. Identification and functional characterization of new potentially defective alleles of human CYP2C19. Pharmacogenetics 2002;12:703-11.

49. Goldstein JA. Clinical relevance of genetic polymorphisms in the human CYP2C subfamily. Br J Clin Pharmacol 2001;52:349-55.

50. Scholz I, Oberwittler H, Riedel KD, et al. Pharmacokinetics, metabolism and bioavailability of the triazole antifungal agent voriconazole in relation to CYP2C19 genotype. Br J Clin Pharmacol 2009;68:906-15.

51. Wang G, Lei HP, Li Z, et al. The CYP2C19 ultra-rapid metabolizer genotype influences the pharmacokinetics of voriconazole in healthy male volunteers. Eur J Clin Pharmacol 2009;65:281-5.

52. Mikus G, Scholz IM, Weiss J. Pharmacogenomics of the triazole antifungal agent voriconazole. Pharmacogenomics 2011;12:861-72.

53. de Morais SM, Wilkinson GR, Blaisdell J, Nakamura K, Meyer UA, Goldstein JA. The major genetic defect responsible for the polymorphism of S-mephenytoin metabolism in humans. J Biol Chem 1994;269:15419-22.

54. Pedersen RS, Brasch-Andersen C, Sim SC, et al. Linkage disequilibrium between the CYP2C19*17 allele and wildtype CYP2C8 and CYP2C9 alleles: Identification of CYP2C haplotypes in healthy Nordic populations. Eur J Clin Pharmacol 2010;66:1199-205.

55. Lee S, Kim BH, Nam WS, et al. Effect of CYP2C19 Polymorphism on the pharmacokinetics of voriconazole after single and multiple doses in healthy volunteers. J Clin Pharmacol 2012;52:195-203.

56. Chen L, Qin S, Xie J, et al. Genetic polymorphism analysis of CYP2C19 in Chinese Han populations from different geographic areas of mainland China. Pharmacogenomics 2008;9:691-702.

57. Kimura M, Ieiri I, Mamiya K, Urae A, Higuchi S. Genetic polymorphism of cytochrome P450s, CYP2C19, and CYP2C9 in a Japanese population. Ther Drug Monit 1998;20:243-7.

58. Zonios D, Yamazaki H, Murayama N, et al. Voriconazole metabolism, toxicity, and the effect of cytochrome P450 2C19 genotype. J Infect Dis 2014;209:1941-8.

59. Pai MP, Allen S. Voriconazole inhibition of tacrolimus metabolism. Clin Infect Dis 2003;36:1089-91.

60. Miyakis S, van Hal SJ, Solvag CJ, Ray J, Marriott D. Clinician ordering practices for voriconazole therapeutic drug monitoring: Experiences of a referral laboratory. Ther Drug Monit 2010;32:661-4.

61. Li Y, Theuretzbacher U, Clancy CJ, Nguyen MH, Derendorf H. Pharmacokinetic/pharmacodynamic profile of posaconazole. Clin Pharmacokinet 2010;49:379-96.

62. Courtney R, Pai S, Laughlin M, Lim J, Batra V. Pharmacokinetics, safety, and tolerability of oral posaconazole administered in single and multiple doses in healthy adults. Antimicrob Agents Chemother 2003;47:2788-95.

63. Courtney R, Wexler D, Radwanski E, Lim J, Laughlin M. Effect of food on the relative bioavailability of two oral formulations of posaconazole in healthy adults. Br J Clin Pharmacol 2004;57:218-22.

64. Walravens J, Brouwers J, Spriet I, Tack J, Annaert P, Augustijns P. Effect of $\mathrm{pH}$ and comedication on gastrointestinal absorption of posaconazole: Monitoring of intraluminal and plasma drug concentrations. Clin Pharmacokinet 2011;50:725-34.

65. Krishna GM, Martinho M, O'Mara E. Improved bioavailibility of posaconazole new tablet and capsule formulation realtive to oral suspension (abstract 574). 52nd ICAAC, 2012. San Francisco CA

66. Conte JE Jr, DeVoe C, Little E, Golden JA. Steady-state intrapulmonary pharmacokinetics and pharmacodynamics of posaconazole in lung transplant recipients. Antimicrob Agents Chemother 2010;54:3609-13.

67. Krishna G, Martinho M, Chandrasekar P, Ullmann AJ, Patino H. Pharmacokinetics of oral posaconazole in allogeneic hematopoietic stem cell transplant recipients with graft-versus-host disease. Pharmacotherapy 2007;27:1627-36.

68. Noxafil@ (posaconazole) [product insert]. Kenilworth: Schering Corporation, 2008.

69. Courtney R, Sansone A, Smith W, et al. Posaconazole pharmacokinetics, safety, and tolerability in subjects with varying degrees of chronic renal disease. J Clin Pharmacol 2005;45:185-92.

70. Gubbins PO, Krishna G, Sansone-Parsons A, et al. Pharmacokinetics and safety of oral posaconazole in neutropenic stem cell transplant recipients. Antimicrob Agents Chemother 2006;50:1993-9.

71. Ullmann AJ, Cornely OA, Burchardt A, et al. Pharmacokinetics, safety, and efficacy of posaconazole in patients with persistent febrile neutropenia or refractory invasive fungal infection. Antimicrob Agents Chemother 2006;50:658-66.

72. Vehreschild JJ, Muller C, Farowski F, et al. Factors influencing the pharmacokinetics of prophylactic posaconazole oral suspension in patients with acute myeloid leukemia or myelodysplastic syndrome. Eur J Clin Pharmacol 2012;68:987-95.

73. Shields RK, Clancy CJ, Vadnerkar A, et al. Posaconazole serum concentrations among cardiothoracic transplant recipients: Factors impacting trough levels and correlation with clinical response to therapy. Antimicrob Agents Chemother 2011;55:1308-11.

74. Moton A, Krishna G, Ma L, et al. Pharmacokinetics of a single dose of the antifungal posaconazole as oral suspension in subjects with hepatic impairment. Curr Med Res Opin 2010;26:1-7.

75. Dodds-Ashley E. Management of drug and food interactions with azole antifungal agents in transplant recipients. Pharmacotherapy 2010;30:842-54.

76. Cronin S, Chandrasekar PH. Safety of triazole antifungal drugs in patients with cancer. J Antimicrob Chemother 2010;65:410-6.

77. Gubbins PO, McConnell SA, Gurley BJ, et al. Influence of grapefruit juice on the systemic availability of itraconazole oral solution in healthy adult volunteers. Pharmacotherapy 2004;24:460-7.

78. Romero AJ, Le Pogamp P, Nilsson LG, Wood N. Effect of voriconazole on the pharmacokinetics of cyclosporine in renal transplant patients. Clin Pharmacol Ther 2002;71:226-34.

79. Wingard JR, Nash RA, Przepiorka D, et al. Relationship of tacrolimus (FK506) whole blood concentrations and efficacy and safety after HLA-identical sibling bone marrow transplantation. Biol Blood Marrow Transplant 1998;4:157-63.

80. Rengelshausen J, Banfield M, Riedel KD, et al. Opposite effects of short-term and long-term St John's wort intake on voriconazole pharmacokinetics. Clin Pharmacol Ther 2005;78:25-33.

81. Johnson LB, Kauffman CA. Voriconazole: A new triazole antifungal agent. Clin Infect Dis 2003;36:630-7.

82. Krishna G, Parsons A, Kantesaria B, Mant T. Evaluation of the pharmacokinetics of posaconazole and rifabutin following co-administration to healthy men. Curr Med Res Opin 2007;23:545-52.

83. Krishna G, Sansone-Parsons A, Kantesaria B. Drug interaction assessment following concomitant administration of posaconazole and phenytoin in healthy men. Curr Med Res Opin 2007;23:1415-22.

84. Cartledge JD, Midgely J, Gazzard BG. Itraconazole solution: Higher serum drug concentrations and better clinical response rates than the capsule formulation in acquired immunodeficiency syndrome patients with candidosis. J Clin Pathol 1997;50:477-80.

85. Glasmacher A, Hahn C, Molitor E, Marklein G, Sauerbruch T, Schmidt-Wolf IG. Itraconazole trough concentrations in antifungal prophylaxis with six different dosing regimens using hydroxypropylbeta-cyclodextrin oral solution or coated-pellet capsules. Mycoses 1999;42:591-600.

86. Graybill JR. Is there a correlation between serum antifungal drug concentration and clinical outcome? J Infect 1994;28(Suppl 1):17-24.

87. Lestner JM, Roberts SA, Moore CB, Howard SJ, Denning DW, Hope WW. Toxicodynamics of itraconazole: Implications for therapeutic drug monitoring. Clin Infect Dis 2009;49:928-30. 
88. Walsh TJ, Anaissie EJ, Denning DW, et al. Treatment of aspergillosis: Clinical practice guidelines of the Infectious Diseases Society of America. Clin Infect Dis 2008;46:327-60.

89. Maertens J, Marchetti O, Herbrecht R, et al. European guidelines for antifungal management in leukemia and hematopoietic stem cell transplant recipients: summary of the ECIL 3 - 2009 update. Bone Marrow Transplant 2011;46:709-18.

90. Herbrecht R, Denning DW, Patterson TF, et al. Voriconazole versus amphotericin B for primary therapy of invasive aspergillosis. N Engl J Med 2002;347:408-15.

91. Kullberg BJ, Sobel JD, Ruhnke M, et al. Voriconazole versus a regimen of amphotericin $\mathrm{B}$ followed by fluconazole for candidaemia in non-neutropenic patients: A randomised non-inferiority trial. Lancet 2005;366:1435-42.

92. Cornely OA, Bassetti M, Calandra T, et al. ESCMID* guideline for the diagnosis and management of Candida diseases 2012: Non-neutropenic adult patients. Clin Microbiol Infect 2012;18(Suppl 7):19-37.

93. Bow EJ, Evans G, Fuller J, et al. Canadian clinical practice guidelines for invasive candidiasis in adults. Can J Infect Dis Med Microbiol 2010;21:e122-50

94. Marks DI, Pagliuca A, Kibbler CC, et al. Voriconazole versus itraconazole for antifungal prophylaxis following allogeneic haematopoietic stem-cell transplantation. Br J Haematol 2011;155:318-27.

95. Wingard JR, Carter SL, Walsh TJ, et al. Randomized, double-blind trial of fluconazole versus voriconazole for prevention of invasive fungal infection after allogeneic hematopoietic cell transplantation. Blood 2010;116:5111-8

96. Walsh TJ, Pappas P, Winston DJ, et al. Voriconazole compared with liposomal amphotericin B for empirical antifungal therapy in patients with neutropenia and persistent fever. N Engl J Med 2002;346:225-34

97. Pascual A, Calandra T, Bolay S, Buclin T, Bille J, Marchetti O. Voriconazole therapeutic drug monitoring in patients with invasive mycoses improves efficacy and safety outcomes. Clin Infect Dis 2008;46:201-11.

98. Racil Z, Winterova J, Kouba M, et al. Monitoring trough voriconazole plasma concentrations in haematological patients: Real life multicentre experience. Mycoses 2012;55:483-92.

99. Smith J, Safdar N, Knasinski V, et al. Voriconazole therapeutic drug monitoring. Antimicrob Agents Chemother 2006;50:1570-2.

100. Troke PF, Hockey HP, Hope WW. Observational study of the clinical efficacy of voriconazole and its relationship to plasma concentrations in patients. Antimicrob Agents Chemother 2011;55:4782-8.

101. Ueda K, Nannya Y, Kumano K, et al. Monitoring trough concentration of voriconazole is important to ensure successful antifungal therapy and to avoid hepatic damage in patients with hematological disorders. Int J Hematol 2009;89:592-9.

102. Walsh TJ, Raad I, Patterson TF, et al. Treatment of invasive aspergillosis with posaconazole in patients who are refractory to or intolerant of conventional therapy: An externally controlled trial. Clin Infect Dis 2007;44:2-12.

103. Cornely OA, Maertens J, Winston DJ, et al. Posaconazole vs. fluconazole or itraconazole prophylaxis in patients with neutropenia. N Engl J Med 2007;356:348-59.

104. Ullmann AJ, Lipton JH, Vesole DH, et al. Posaconazole or fluconazole for prophylaxis in severe graft-versus-host disease. N Engl J Med 2007;356:335-47.

105. Krishna G, AbuTarif M, Xuan F, Martinho M, Angulo D, Cornely OA. Pharmacokinetics of oral posaconazole in neutropenic patients receiving chemotherapy for acute myelogenous leukemia or myelodysplastic syndrome. Pharmacotherapy 2008;28:1223-32.

106. Jang SH, Colangelo PM, Gobburu JV. Exposure-response of posaconazole used for prophylaxis against invasive fungal infections: Evaluating the need to adjust doses based on drug concentrations in plasma. Clin Pharmacol Ther 2010;88:115-9.

107. Bryant AM, Slain D, Cumpston A, Craig M. A post-marketing evaluation of posaconazole plasma concentrations in neutropenic patients with haematological malignancy receiving posaconazole prophylaxis. Int J Antimicrob Agents 2011;37:266-9.

108. Dolton MJ, Ray JE, Marriott D, McLachlan AJ. Posaconazole exposure-response relationship: Evaluating the utility of therapeutic drug monitoring. Antimicrob Agents Chemother 2012;56:2806-13.

109. Pascual A, Csajka C, Buclin T, et al. Challenging recommended oral and intravenous voriconazole doses for improved efficacy and safety: population pharmacokinetics-based analysis of adult patients with invasive fungal infections. Clin Infect Dis 2012;55:381-90.
110. Dolton MJ, Ray JE, Chen SC, Ng K, Pont L, McLachlan AJ. Multicenter study of posaconazole therapeutic drug monitoring: Exposure-response relationship and factors affecting concentration. Antimicrob Agents Chemother 2012;56:5503-10.

111. Pagano L, Caira M, Candoni A, et al. The epidemiology of fungal infections in patients with hematologic malignancies: The SEIFEM-2004 study. Haematologica 2006;91:1068-75.

112. Michallet M, Ito JI. Approaches to the management of invasive fungal infections in hematologic malignancy and hematopoietic cell transplantation. J Clin Oncol 2009;27:3398-409.

113. Marr KA, Carter RA, Boeckh M, Martin P, Corey L. Invasive aspergillosis in allogeneic stem cell transplant recipients: Changes in epidemiology and risk factors. Blood 2002;100:4358-66.

114. Lin SJ, Schranz J, Teutsch SM. Aspergillosis case-fatality rate: Systematic review of the literature. Clin Infect Dis 2001;32:358-66.

115. Vardakas KZ, Michalopoulos A, Falagas ME. Fluconazole versus itraconazole for antifungal prophylaxis in neutropenic patients with haematological malignancies: A meta-analysis of randomisedcontrolled trials. Br J Haematol 2005;131:22-8.

116. Mattiuzzi GN, Cortes J, Alvarado G, et al. Efficacy and safety of intravenous voriconazole and intravenous itraconazole for antifungal prophylaxis in patients with acute myelogenous leukemia or high-risk myelodysplastic syndrome. Support Care Cancer 2011;19:19-26.

117. Even C, Bastuji-Garin S, Hicheri Y, et al. Impact of invasive fungal disease on the chemotherapy schedule and event-free survival in acute leukemia patients who survived fungal disease: A case-control study. Haematologica 2011;96:337-41.

118. Nivoix Y, Ubeaud-Sequier G, Engel P, Leveque D, Herbrecht R. Drug-drug interactions of triazole antifungal agents in multimorbid patients and implications for patient care. Curr Drug Metab 2009;10:395-409.

119. Gubbins PO, Heldenbrand S. Clinically relevant drug interactions of current antifungal agents. Mycoses 2010;53:95-113.

120. Boogaerts MA, Verhoef GE, Zachee P, Demuynck H, Verbist L, De Beule K. Antifungal prophylaxis with itraconazole in prolonged neutropenia: Correlation with plasma levels. Mycoses 1989;32(Suppl 1):103-8.

121. Glasmacher A, Hahn C, Leutner C, et al. Breakthrough invasive fungal infections in neutropenic patients after prophylaxis with itraconazole. Mycoses 1999;42:443-51.

122. Trifilio S, Singhal S, Williams S, et al. Breakthrough fungal infections after allogeneic hematopoietic stem cell transplantation in patients on prophylactic voriconazole. Bone Marrow Transplant 2007;40:451-6.

123. Campoli P, Perlin DS, Kristof AS, White TC, Filler SG, Sheppard DC. Pharmacokinetics of posaconazole within epithelial cells and fungi: Insights into potential mechanisms of action during treatment and prophylaxis. J Infect Dis 2013;208:1717-28.

124. Winston DJ, Maziarz RT, Chandrasekar PH, et al. Intravenous and oral itraconazole versus intravenous and oral fluconazole for longterm antifungal prophylaxis in allogeneic hematopoietic stem-cell transplant recipients. A multicenter, randomized trial. Ann Intern Med 2003;138:705-13.

125. Bose P, Parekh HD, Holter JL, Greenfield RA. Disseminated fusariosis occurring in two patients despite posaconazole prophylaxis. J Clin Microbiol 2011;49:1674-5.

126. Berge M, Guillemain R, Boussaud V, et al. Voriconazole pharmacokinetic variability in cystic fibrosis lung transplant patients. Transpl Infect Dis 2009;11:211-9.

127. Shimizu T, Ochiai H, Asell F, et al. Bioinformatics research on inter-racial difference in drug metabolism I. Analysis on frequencies of mutant alleles and poor metabolizers on CYP2D6 and CYP2C19. Drug Metab Pharmacokinet 2003;18:48-70.

128. Hoenigl M, Duettmann W, Raggam RB, et al. Potential factors for inadequate voriconazole plasma concentrations in intensive care unit patients and patients with hematological malignancies. Antimicrob Agents Chemother 2013;57:3262-7.

129. Brett J, Chong O, Graham GG, et al. Antifungal use and therapeutic monitoring of plasma concentrations of itraconazole in heart and lung transplantation patients. Ther Drug Monit 2013;35:133-6.

130. Hussaini T, Ruping MJ, Farowski F, Vehreschild JJ, Cornely OA. Therapeutic drug monitoring of voriconazole and posaconazole. Pharmacotherapy 2011;31:214-25.

131. Mitsani D, Nguyen MH, Shields RK, et al. Prospective, observational study of voriconazole therapeutic drug monitoring 
among lung transplant recipients receiving prophylaxis: Factors impacting levels of and associations between serum troughs, efficacy, and toxicity. Antimicrob Agents Chemother 2012;56:2371-7.

132. Canafax DM, Graves NM, Hilligoss DM, Carleton BC, Gardner MJ, Matas AJ. Interaction between cyclosporine and fluconazole in renal allograft recipients. Transplantation 1991:51:1014-8.

133. Toda F, Tanabe K, Ito S, et al. Tacrolimus trough level adjustment after administration of fluconazole to kidney recipients. Transplant Proc 2002;34:1733-5.

134. Manez R, Martin M, Raman D, et al. Fluconazole therapy in transplant recipients receiving FK506. Transplantation 1994;57:1521-3.

135. Cervelli MJ. Fluconazole-sirolimus drug interaction. Transplantation 2002;74:1477-8.

136. Sadaba B, Campanero MA, Quetglas EG, Azanza JR. Clinical relevance of sirolimus drug interactions in transplant patients. Transplant Proc 2004;36:3226-8.

137. Kramer MR, Marshall SE, Denning DW, et al. Cyclosporine and itraconazole interaction in heart and lung transplant recipients. Ann Intern Med 1990;113:327-9.

138. Banerjee R, Leaver N, Lyster H, Banner NR. Coadministration of itraconazole and tacrolimus after thoracic organ transplantation. Transplant Proc 2001;33:1600-2.

139. Tintillier M, Kirch L, Goffin E, Cuvelier C, Pochet JM. Interaction between voriconazole and tacrolimus in a kidney-transplanted patient. Nephrol Dial Transplant 2005;20:664-5.

140. Surowiec D, DePestel DD, Carver PL. Concurrent administration of sirolimus and voriconazole: A pilot study assessing safety and approaches to appropriate management. Pharmacotherapy 2008;28:719-29.

141. Sansone-Parsons A, Krishna G, Martinho M, Kantesaria B, Gelone S, Mant TG. Effect of oral posaconazole on the pharmacokinetics of cyclosporine and tacrolimus. Pharmacotherapy 2007;27:825-34.

142. Alexander BD, Perfect JR, Daly JS, et al. Posaconazole as salvage therapy in patients with invasive fungal infections after solid organ transplant. Transplantation 2008;86:791-6.

143. Moton A, Ma L, Krishna G, Martinho M, Seiberling M, McLeod J. Effects of oral posaconazole on the pharmacokinetics of sirolimus. Curr Med Res Opin 2009;25:701-7.

144. Dahlan R, Patel A, Haider S. Successful use of posaconazole to treat invasive cutaneous fungal infection in a liver transplant patient on sirolimus. Can J Infect Dis Med Microbiol 2012;23:e44-7.

145. Baddley JW, Patel M, Bhavnani SM, Moser SA, Andes DR. Association of fluconazole pharmacodynamics with mortality in patients with candidemia. Antimicrob Agents Chemother 2008;52:3022-8.

146. Clancy CJ, Yu VL, Morris AJ, Snydman DR, Nguyen MH. Fluconazole MIC and the fluconazole dose/MIC ratio correlate with therapeutic response among patients with candidemia. Antimicrob Agents Chemother 2005;49:3171-7.

147. Pai MP, Turpin RS, Garey KW. Association of fluconazole area under the concentration-time curve/MIC and dose/MIC ratios with mortality in nonneutropenic patients with candidemia. Antimicrob Agents Chemother 2007;51:35-9.

148. Andes D, Pascual A, Marchetti O. Antifungal therapeutic drug monitoring: Established and emerging indications. Antimicrob Agents Chemother 2009;53:24-34.

149. Andes D, van Ogtrop M. Characterization and quantitation of the pharmacodynamics of fluconazole in a neutropenic murine disseminated candidiasis infection model. Antimicrob Agents Chemother 1999;43:2116-20.

150. Rex JH, Pfaller MA, Galgiani JN, et al. Development of interpretive breakpoints for antifungal susceptibility testing: Conceptual framework and analysis of in vitro-in vivo correlation data for fluconazole, itraconazole, and candida infections. Subcommittee on Antifungal Susceptibility Testing of the National Committee for Clinical Laboratory Standards. Clin Infect Dis 1997;24:235-47.

151. Persat F, Marzullo C, Guyotat D, Rochet MJ, Piens MA. Plasma itraconazole concentrations in neutropenic patients after repeated high-dose treatment. Eur J Cancer 1992;28A:838-41.

152. Smith D, van de Velde V, Woestenborghs R, Gazzard BG. The pharmacokinetics of oral itraconazole in AIDS patients. J Pharm Pharmacol 1992;44:618-9.

153. Koks CH, Meenhorst PL, Bult A, Beijnen JH. Itraconazole solution: Summary of pharmacokinetic features and review of activity in the treatment of fluconazole-resistant oral candidosis in HIV-infected persons. Pharmacol Res 2002;46:195-201.
154. Willems L, van der Geest R, de Beule K. Itraconazole oral solution and intravenous formulations: A review of pharmacokinetics and pharmacodynamics. J Clin Pharm Ther 2001;26:159-69.

155. Berenguer J, Ali NM, Allende MC, et al. Itraconazole for experimental pulmonary aspergillosis: Comparison with amphotericin B, interaction with cyclosporin A, and correlation between therapeutic response and itraconazole concentrations in plasma. Antimicrob Agents Chemother 1994;38:1303-8.

156. Denning DW, Follansbee SE, Scolaro M, Norris S, Edelstein H, Stevens DA. Pulmonary aspergillosis in the acquired immunodeficiency syndrome. N Engl J Med 1991;324:654-62.

157. Tricot G, Joosten E, Boogaerts MA, Vande Pitte J, Cauwenbergh G. Ketoconazole vs. itraconazole for antifungal prophylaxis in patients with severe granulocytopenia: Preliminary results of two nonrandomized studies. Rev Infect Dis 1987;9(Suppl 1):S94-9.

158. Simon A, Besuden M, Vezmar S, et al. Itraconazole prophylaxis in pediatric cancer patients receiving conventional chemotherapy or autologous stem cell transplants. Support Care Cancer 2007;15:213-20.

159. Baietto L, G De Rosa F, D’Avolio A, et al. Prophylactic drug monitoring of itraconazole in an oncohematological pediatric patient population. Ther Drug Monit 2012;34:604-6.

160. Muldrew KM, Maples HD, Stowe CD, Jacobs RF. Intravenous voriconazole therapy in a preterm infant. Pharmacotherapy 2005;25:893-8.

161. Santos RP, Sanchez PJ, Mejias A, et al. Successful medical treatment of cutaneous aspergillosis in a premature infant using liposomal amphotericin B, voriconazole and micafungin. Pediatr Infect Dis J 2007;26:364-6.

162. Walsh TJ, Lutsar I, Driscoll T, et al. Voriconazole in the treatment of aspergillosis, scedosporiosis and other invasive fungal infections in children. Pediatr Infect Dis J 2002;21:240-8.

163. Karlsson MO, Lutsar I, Milligan PA. Population pharmacokinetic analysis of voriconazole plasma concentration data from pediatric studies. Antimicrob Agents Chemother 2009;53:935-44.

164. Pieper S, Kolve H, Gumbinger HG, Goletz G, Wurthwein G, Groll AH. Monitoring of voriconazole plasma concentrations in immunocompromised paediatric patients. J Antimicrob Chemother 2012;67:2717-24

165. Spriet I, Cosaert K, Renard M, et al. Voriconazole plasma levels in children are highly variable. Eur J Clin Microbiol Infect Dis 2011;30:283-7.

166. Yanni SB, Annaert PP, Augustijns P, Ibrahim JG, Benjamin DK Jr, Thakker DR. In vitro hepatic metabolism explains higher clearance of voriconazole in children versus adults: Role of CYP2C19 and flavin-containing monooxygenase 3. Drug Metab Dispos 2010;38:25-31.

167. Weiss J, Ten Hoevel MM, Burhenne J, et al. CYP2C19 genotype is a major factor contributing to the highly variable pharmacokinetics of voriconazole. J Clin Pharmacol 2009;49:196-204.

168. Aitken AE, Morgan ET. Gene-specific effects of inflammatory cytokines on cytochrome P450 2C, 2B6 and 3A4 mRNA levels in human hepatocytes. Drug Metab Dispos 2007;35:1687-93.

169. Carcillo JA, Doughty L, Kofos D, et al. Cytochrome P450 mediateddrug metabolism is reduced in children with sepsis-induced multiple organ failure. Intensive Care Med 2003;29:980-4.

170. Baldwin RM, Ohlsson S, Pedersen RS, et al. Increased omeprazole metabolism in carriers of the CYP2C19*17 allele; a pharmacokinetic study in healthy volunteers. Br J Clin Pharmacol 2008;65:767-74

171. Andes D, Marchillo K, Stamstad T, Conklin R. In vivo pharmacokinetics and pharmacodynamics of a new triazole, voriconazole, in a murine candidiasis model. Antimicrob Agents Chemother 2003:47:3165-9.

172. Chen J, Chan C, Colantonio D, Seto W. Therapeutic drug monitoring of voriconazole in children. Ther Drug Monit 2012;34:77-84.

173. Imhof A, Schaer DJ, Schanz U, Schwarz U. Neurological adverse events to voriconazole: Evidence for therapeutic drug monitoring. Swiss Med Wkly 2006;136(45-46):739-42.

174. Trifilio S, Pennick G, Pi J, et al. Monitoring plasma voriconazole levels may be necessary to avoid subtherapeutic levels in hematopoietic stem cell transplant recipients. Cancer 2007;109:1532-5.

175. Neely M, Rushing T, Kovacs A, Jelliffe R, Hoffman J. Voriconazole pharmacokinetics and pharmacodynamics in children. Clin Infect Dis 2010;50:27-36. 
176. Boyd AE, Modi S, Howard SJ, Moore CB, Keevil BG, Denning DW. Adverse reactions to voriconazole. Clin Infect Dis 2004;39:1241-4.

177. Zonios DI, Gea-Banacloche J, Childs R, Bennett JE. Hallucinations during voriconazole therapy. Clin Infect Dis 2008;47:e7-e10.

178. Tan K, Brayshaw N, Tomaszewski K, Troke P, Wood N. Investigation of the potential relationships between plasma voriconazole concentrations and visual adverse events or liver function test abnormalities. J Clin Pharmacol 2006;46:235-43.

179. Dolton MJ, Ray JE, Chen SC, Ng K, Pont LG, McLachlan AJ. Multicenter study of voriconazole pharmacokinetics and therapeutic drug monitoring. Antimicrob Agents Chemother 2012;56:4793-9.

180. Walsh TJ, Karlsson MO, Driscoll T, et al. Pharmacokinetics and safety of intravenous voriconazole in children after single- or multiple-dose administration. Antimicrob Agents Chemother 2004;48:2166-72.

181. Walsh TJ, Driscoll T, Milligan PA, et al. Pharmacokinetics, safety, and tolerability of voriconazole in immunocompromised children. Antimicrob Agents Chemother 2010;54:4116-23.

182. Bruggemann RJ, van der Linden JW, Verweij PE, Burger DM, Warris A. Impact of therapeutic drug monitoring of voriconazole in a pediatric population. Pediatr Infect Dis J 2011;30:533-4

183. Bartelink IH, Wolfs T, Jonker M, et al. Highly variable plasma concentrations of voriconazole in pediatric hematopoietic stem cell transplantation patients. Antimicrob Agents Chemother 2013;57:235-40.

184. Doring M, Muller C, Johann PD, et al. Analysis of posaconazole as oral antifungal prophylaxis in pediatric patients under 12 years of age following allogeneic stem cell transplantation. BMC Infect Dis 2012;12:263.

185. Dodds Ashley ES, Varkey JB, Krishna G, et al. Pharmacokinetics of posaconazole administered orally or by nasogastric tube in healthy volunteers. Antimicrob Agents Chemother 2009;53:2960-4.

186. Brammer KW, Coakley AJ, Jezequel SG, Tarbit MH. The disposition and metabolism of [14C]fluconazole in humans. Drug Metab Dispos 1991;19:764-7.

187. Debruyne D, Ryckelynck JP. Clinical pharmacokinetics of fluconazole. Clin Pharmacokinet 1993;24:10-27.

188. Isoherranen N, Kunze KL, Allen KE, Nelson WL, Thummel KE. Role of itraconazole metabolites in CYP3A4 inhibition. Drug Metab Dispos 2004:32:1121-31.

189. Boogaerts MA, Maertens J, Van Der Geest R, et al. Pharmacokinetics and safety of a 7-day administration of intravenous itraconazole followed by a 14-day administration of itraconazole oral solution in patients with hematologic malignancy. Antimicrob Agents Chemother 2001;45:981-5.

190. Conway SP, Etherington C, Peckham DG, Brownlee KG, Whitehead A, Cunliffe H. Pharmacokinetics and safety of itraconazole in patients with cystic fibrosis. J Antimicrob Chemother 2004;53:841-7.

191. Michallet M, Persat F, Kranzhofer N, et al. Pharmacokinetics of itraconazole oral solution in allogeneic bone marrow transplant patients receiving total body irradiation. Bone Marrow Transplant 1998;21:1239-43.

192. Mino Y, Naito T, Watanabe T, et al. Hydroxy-itraconazole pharmacokinetics is similar to that of itraconazole in immunocompromised patients receiving oral solution of itraconazole. Clin Chim Acta 2013;415:128-32.

193. Suarez-Kurtz G, Bozza FA, Vicente FL, Ponte CG, Struchiner CJ. Limited-sampling strategy models for itraconazole and hydroxy-itraconazole based on data from a bioequivalence study. Antimicrob Agents Chemother 1999;43:134-40.

194. Vandewoude K, Vogelaers D, Decruyenaere J, et al. Concentrations in plasma and safety of 7 days of intravenous itraconazole followed by 2 weeks of oral itraconazole solution in patients in intensive care units. Antimicrob Agents Chemother 1997;41:2714-8.

195. Odds FC, Bossche HV. Antifungal activity of itraconazole compared with hydroxy-itraconazole in vitro. J Antimicrob Chemother 2000;45:371-3.

196. Breadmore MC, Thormann W. Capillary electrophoresis evidence for the stereoselective metabolism of itraconazole in man. Electrophoresis 2003;24:2588-97.

197. Roffey SJ, Cole S, Comby P, et al. The disposition of voriconazole in mouse, rat, rabbit, guinea pig, dog, and human. Drug Metab Dispos 2003;31:731-41.

198. Vfend ${ }^{\circledR}$ (voriconazole) [package insert]. Kirkland, Quebec: Pfizer Canada, Inc; 2013.
199. Eiden C, Cociglio M, Hillaire-Buys D, et al. Pharmacokinetic variability of voriconazole and $\mathrm{N}$-oxide voriconazole measured as therapeutic drug monitoring. Xenobiotica 2010;40:701-6.

200. Hassan A, Burhenne J, Riedel KD, et al. Modulators of very low voriconazole concentrations in routine therapeutic drug monitoring. Ther Drug Monit 2011;33:86-93.

201. Yamada T, Mino Y, Yagi T, Naito T, Kawakami J. Rapid simultaneous determination of voriconazole and its $\mathrm{N}$-oxide in human plasma using an isocratic high-performance liquid chromatography method and its clinical application. Clin Biochem 2012;45:134-8.

202. Meletiadis J, Chanock S, Walsh TJ. Human pharmacogenomic variations and their implications for antifungal efficacy. Clin Microbiol Rev 2006;19:763-87.

203. Cowen EW, Nguyen JC, Miller DD, et al. Chronic phototoxicity and aggressive squamous cell carcinoma of the skin in children and adults during treatment with voriconazole. J Am Acad Dermatol 2010;62:31-7.

204. Denning DW, Griffiths CE. Muco-cutaneous retinoid-effects and facial erythema related to the novel triazole antifungal agent voriconazole. Clin Exp Dermatol 2001;26:648-53.

205. Epaulard O, Leccia MT, Blanche S, et al. Phototoxicity and photocarcinogenesis associated with voriconazole. Med Mal Infect 2011;41:639-45

206. Schmutz JL, Trechot P. [Careful: Skins cancers and voriconazole]. Ann Dermatol Venereol 2011;138:805-6.

207. Ghosal A, Hapangama N, Yuan Y, et al. Identification of human UDP-glucuronosyltransferase enzyme(s) responsible for the glucuronidation of posaconazole (Noxafil). Drug Metab Dispos 2004;32:267-71.

208. Krieter P, Flannery B, Musick T, Gohdes M, Martinho M, Courtney R. Disposition of posaconazole following single-dose oral administration in healthy subjects. Antimicrob Agents Chemother 2004:48:3543-51.

209. Hulsewede JW, Dermoumi H. Serum level determination of fluconazole by high-performance liquid chromatography and bioassay. Zentralbl Bakteriol 1996;283:492-6.

210. Marchetti O, Majcherczyk PA, Glauser MP, Bille J, Moreillon P, Sanglard D. Sensitive bioassay for determination of fluconazole concentrations in plasma using a Candida albicans mutant hypersusceptible to azoles. Antimicrob Agents Chemother 2001;45:696-700.

211. Rex JH, Hanson LH, Amantea MA, Stevens DA, Bennett JE. Standardization of a fluconazole bioassay and correlation of results with those obtained by high-pressure liquid chromatography. Antimicrob Agents Chemother 1991;35:846-50.

212. Perea S, Pennick GJ, Modak A, et al. Comparison of highperformance liquid chromatographic and microbiological methods for determination of voriconazole levels in plasma. Antimicrob Agents Chemother 2000;44:1209-13.

213. Pascual A, Nieth V, Calandra T, et al. Variability of voriconazole plasma levels measured by new high-performance liquid chromatography and bioassay methods. Antimicrob Agents Chemother 2007;51:137-43.

214. Steinmann J, Huelsewede J, Buer J, Rath PM. Comparison and evaluation of a novel bioassay and high-performance liquid chromatography for the clinical measurement of serum voriconazole concentrations. Mycoses 2011;54:e421-8.

215. Rochat B, Pascual A, Pesse B, et al. Ultra-performance liquid chromatography mass spectrometry and sensitive bioassay methods for quantification of posaconazole plasma concentrations after oral dosing. Antimicrob Agents Chemother 2010;54:5074-81.

216. British Society for Antimicrobial Chemotherapy Working Party. Laboratory monitoring of antifungal chemotherapy. Lancet 1991;337:1577-80.

217. Warnock DW, Turner A, Burke J. Comparison of high performance liquid chromatographic and microbiological methods for determination of itraconazole. J Antimicrob Chemother 1988;21:93-100.

218. Hostetler JS, Heykants J, Clemons KV, Woestenborghs R, Hanson LH, Stevens DA. Discrepancies in bioassay and chromatography determinations explained by metabolism of itraconazole to hydroxyitraconazole: Studies of interpatient variations in concentrations. Antimicrob Agents Chemother 1993;37:2224-7.

219. Hulsewede JW, Dermoumi H, Ansorg R. Determination of itraconazole and hydroxy-itraconazole in sera using highperformance-liquid-chromatography and a bioassay. Zentralbl Bakteriol 1995;282:457-64. 
220. Law D, Moore CB, Denning DW. Discrepancies associated with the measurement of itraconazole serum concentrations by bioassays. J Antimicrob Chemother 1999:44:577-8.

221. Law D, Moore CB, Denning DW. Bioassay for serum itraconazole concentrations using hydroxyitraconazole standards. Antimicrob Agents Chemother 1994;38:1561-6.

222. Odds FC, Dupont B, Rinaldi MG, Stevens DA, Warnock DW, Woestenborghs R. Bioassays for itraconazole blood levels: An interlaboratory collaborative study. J Antimicrob Chemother 1999;43:723-7.

223. Ekiert RJ, Krzek J, Talik P. Chromatographic and electrophoretic techniques used in the analysis of triazole antifungal agents - a review. Talanta 2010;82:1090-100.

224. Decosterd LA, Rochat B, Pesse B, et al. Multiplex ultra-performance liquid chromatography-tandem mass spectrometry method for simultaneous quantification in human plasma of fluconazole, itraconazole, hydroxyitraconazole, posaconazole, voriconazole, voriconazole- $\mathrm{N}$-oxide, anidulafungin, and caspofungin. Antimicrob Agents Chemother 2010;54:5303-15.

225. Farowski F, Cornely OA, Vehreschild JJ, et al. Quantitation of azoles and echinocandins in compartments of peripheral blood by liquid chromatography-tandem mass spectrometry. Antimicrob Agents Chemother 2010;54:1815-9.

226. Bruggemann RJ, Touw DJ, Aarnoutse RE, Verweij PE, Burger DM. International interlaboratory proficiency testing program for measurement of azole antifungal plasma concentrations. Antimicrob Agents Chemother 2009;53:303-5.

227. Gordien JB, Pigneux A, Vigouroux S, et al. Simultaneous determination of five systemic azoles in plasma by high-performance liquid chromatography with ultraviolet detection. J Pharm Biomed Anal 2009;50:932-8.

228. Wissen CP, Burger DM, Verweij PE, Aarnoutse RE, Bruggemann RJ. Simultaneous determination of the azoles voriconazole, posaconazole, isavuconazole, itraconazole and its metabolite hydroxy-itraconazole in human plasma by reversed phase ultra-performance liquid chromatography with ultraviolet detection. J Chromatogr B Analyt Technol Biomed Life Sci 2012;887-888:79-84.
229. Breadmore MC, Prochazkova A, Theurillat R, Thormann W. Determination of itraconazole and hydroxyitraconazole in human serum and plasma by micellar electrokinetic chromatography. J Chromatogr A 2003;1014(1-2):57-70.

230. Lin SC, Lin SW, Chen JM, Kuo CH. Using sweeping-micellar electrokinetic chromatography to determine voriconazole in patient plasma. Talanta 2010;82:653-9.

231. Lin SC, Liu HY, Lin SW, et al. Simultaneous determination of triazole antifungal drugs in human plasma by sweeping-micellar electrokinetic chromatography. Anal Bioanal Chem 2012;404:217-28.

232. Theurillat R, Zimmerli S, Thormann W. Determination of voriconazole in human serum and plasma by micellar electrokinetic chromatography. J Pharm Biomed Anal 2010;53:1313-8.

233. von Heeren F, Tanner R, Theurillat R, Thormann W. Determination of fluconazole in human plasma by micellar electrokinetic capillary chromatography with detection at $190 \mathrm{~nm}$ J Chromatogr A 1996;745(1-2):165-72.

234. Papadoyannis IN, Gika HG. Peak Purity Determination with a Diode Array Detector. J Liq Chromatogr Relat Technol 2005;27:1083-92.

235. European Medicines Agency, Committee for Medicinal Products for Human Use (CHMP). Guideline on bioanalytical method validation. 2011.

236. Food and Drug Administration (FDA), Center for Drug Evaluation and Research, Division of Special Pathogen and Immunologic Drug Products. Voriconazole AC Briefing Document: Background Document for the Antiviral Drug Products Advisory Committee Meeting. 2001.

237. Drusano GL. How does a patient maximally benefit from anti-infective chemotherapy? Clin Infect Dis 2004;39:1245-6.

238. Hardin TC, Graybill JR, Fetchick R, Woestenborghs R, Rinaldi MG, Kuhn JG. Pharmacokinetics of itraconazole following oral administration to normal volunteers. Antimicrob Agents Chemother 1988;32:1310-3.

239. Purkins L, Wood N, Ghahramani P, Greenhalgh K, Allen MJ, Kleinermans D. Pharmacokinetics and safety of voriconazole following intravenous- to oral-dose escalation regimens. Antimicrob Agents Chemother 2002;46:2546-53. 


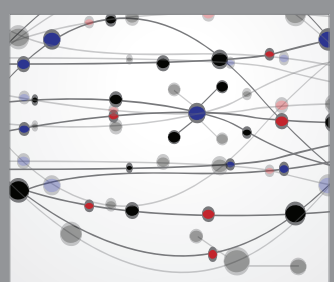

The Scientific World Journal
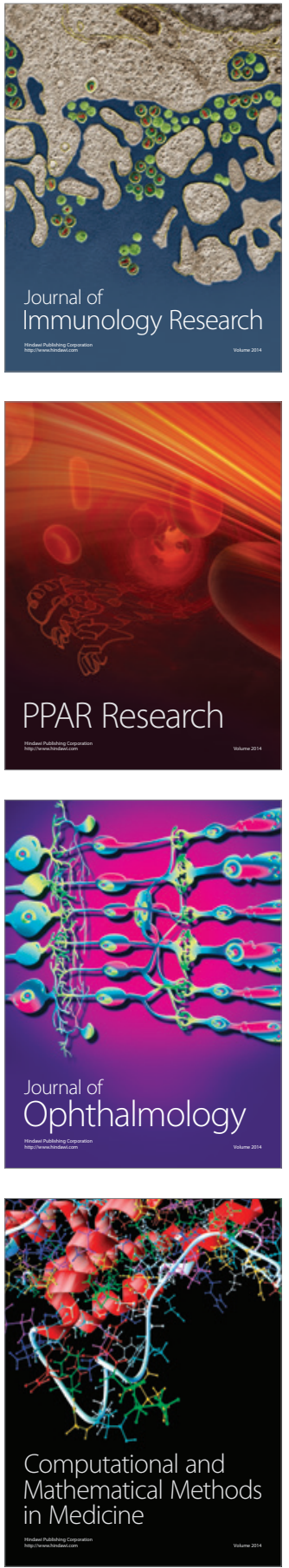

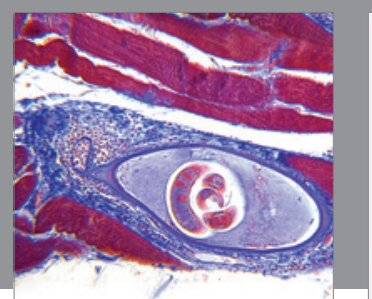

Gastroenterology Research and Practice

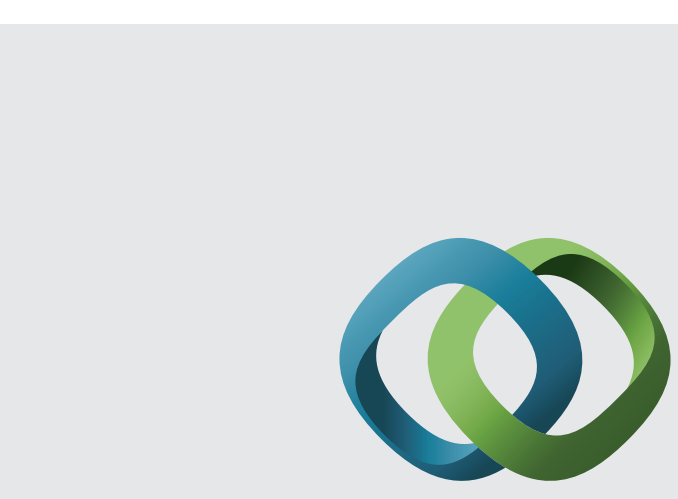

\section{Hindawi}

Submit your manuscripts at

http://www.hindawi.com
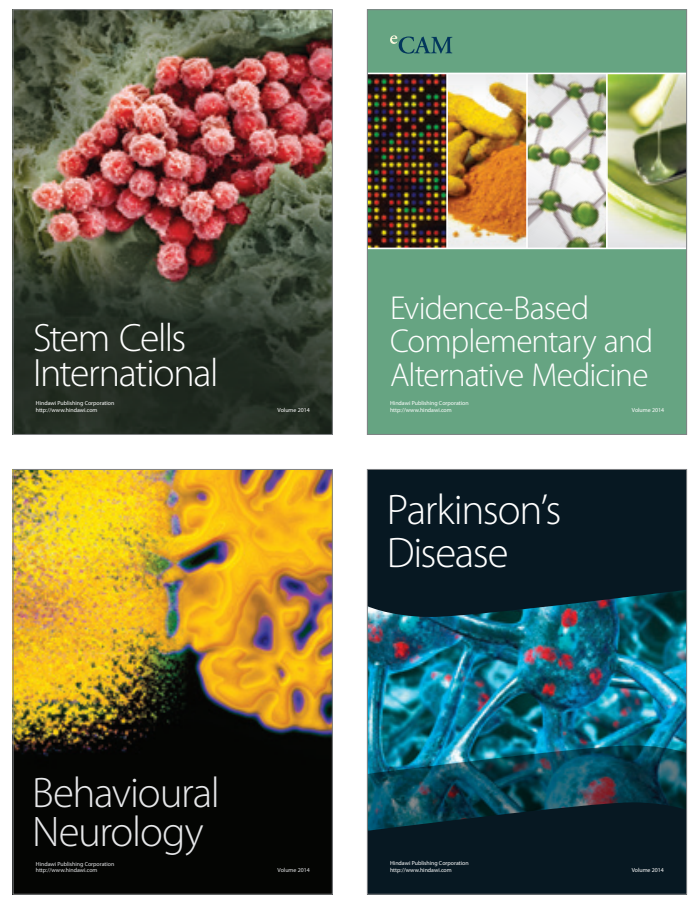
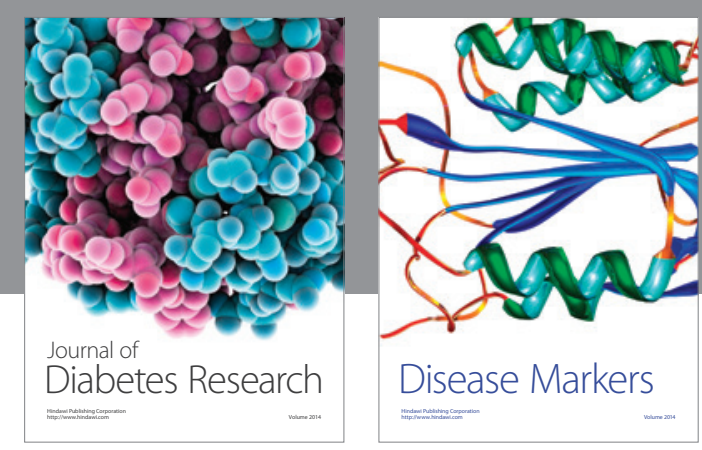

Disease Markers
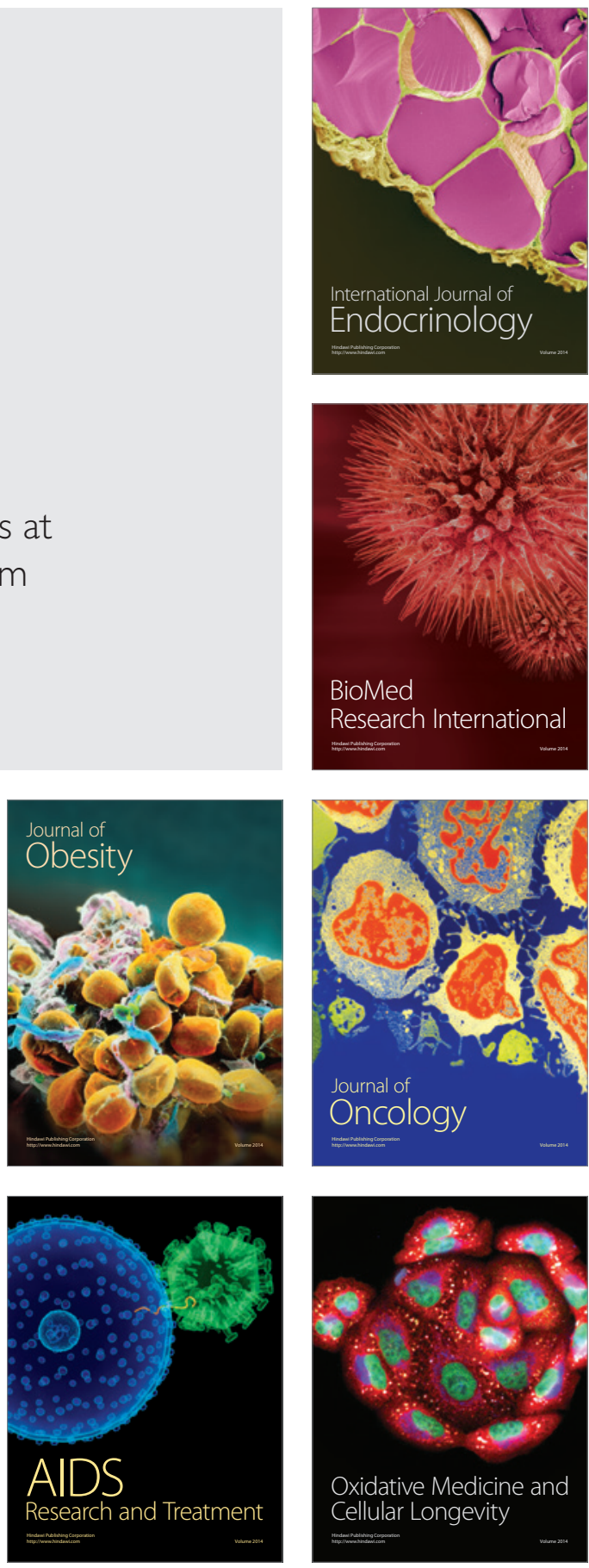